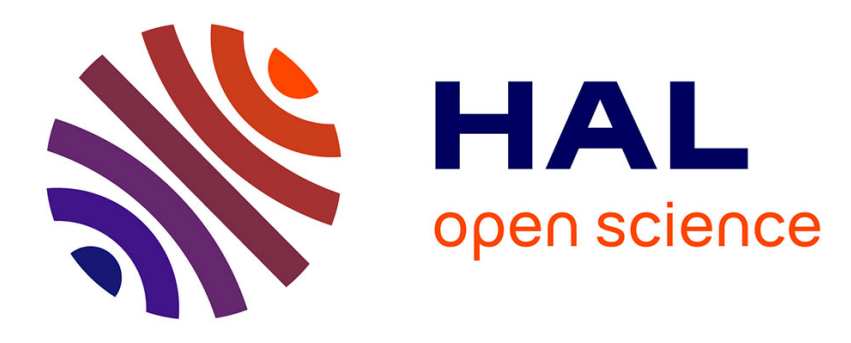

\title{
Forty years of social mobility in France: change in social fluidity in the light of recent models
}

\author{
Louis-André Vallet
}

\section{To cite this version:}

Louis-André Vallet. Forty years of social mobility in France: change in social fluidity in the light of recent models. Revue française de sociologie, 2001, 42 (Supplement), pp.5-64. hal-03455265

\section{HAL Id: hal-03455265 \\ https://hal.science/hal-03455265}

Submitted on 29 Nov 2021

HAL is a multi-disciplinary open access archive for the deposit and dissemination of scientific research documents, whether they are published or not. The documents may come from teaching and research institutions in France or abroad, or from public or private research centers.
L'archive ouverte pluridisciplinaire HAL, est destinée au dépôt et à la diffusion de documents scientifiques de niveau recherche, publiés ou non, émanant des établissements d'enseignement et de recherche français ou étrangers, des laboratoires publics ou privés. 


\title{
Forty years of social mobility in France : change in social fluidity in the light of recent models Louis-André Vallet, Kevin Riley
}

\begin{abstract}
The aim of this paper is to examine whether a long-term trend can be identified in the mobility regime of French society from the middle of the century. It begins with a review of the international literature on temporal trends in social fluidity within modern societies. Analysing recent French research which has concluded that inequality of opportunity has remained unchanged in France during the last two decades, the paper argues that such a conclusion can only have resulted from the use of insufficiently powerful statistical techniques. The second part of the paper analyses father-son and father-daughter mobility tables drawn from national representative surveys carried out in 1953, 1970, 1977, 1985 and 1993 ( $N=35,741$ for males and 18,484 for females). The use of log-linear and log-multiplicative models reveals that the statistical association (as measured with the logarithm of the odds ratio) between social origin and destination has declined steadily by $0.5 \%$ a year over a period of forty years. This finding highlights a slow but continuous trend towards a reduction in inequality of opportunity from the middle of the century. Of the twelve million French men and women between the ages of 35 and 59 who were in employment in 1993, nearly half a million would have belonged to different classes without this forty year increase in social fluidity. The paper concludes that the thesis of temporal invariance in the intergenera- tional mobility regime cannot be maintained for France, but that the reasons of this change still remain to be ascertained.
\end{abstract}

\section{Citer ce document / Cite this document :}

Vallet Louis-André, Riley Kevin. Forty years of social mobility in France : change in social fluidity in the light of recent models. In: Revue française de sociologie, 2001, 42, supplément. An annual english selection. pp. 5-64;

https://www.persee.fr/doc/rfsoc_0035-2969_2001_sup_42_1_5413

Fichier pdf généré le 23/04/2018 
Louis-André VALLET

\title{
Forty Years of Social Mobility in France
}

\author{
Change in Social Fluidity in the Light \\ of Recent Models*
}

\begin{abstract}
The aim of this paper is to examine whether a long-term trend can be identified in the mobility regime of French society from the middle of the century. It begins with a review of the international literature on temporal trends in social fluidity within modern societies. Analysing recent French research which has concluded that inequality of opportunity has remained unchanged in France during the last two decades, the paper argues that such a conclusion can only have resulted from the use of insufficiently powerful statistical techniques. The second part of the paper analyses father-son and father-daughter mobility tables drawn from national representative surveys carried out in 1953,1970,1977, 1985 and 1993 $(\mathrm{N}=35,741$ for males and 18,484 for females). The use of log-linear and log-multiplicative models reveals that the statistical association (as measured with the logarithm of the odds ratio) between social origin and destination has declined steadily by $0.5 \%$ a year over a period of forty years. This finding highlights a slow but continuous trend towards a reduction in inequality of opportunity from the middle of the century. Of the twelve million French men and women between the ages of 35 and 59 who were in employment in 1993, nearly half a million would have belonged to different classes without this forty year increase in social fluidity. The paper concludes that the thesis of temporal invariance in the intergenerational mobility regime cannot be maintained for France, but that the reasons of this change still remain to be ascertained.
\end{abstract}

* This is the English version of an article which appeared in the Revue Française de Sociologie (1999, 40, 1, pp. 5-64) and the author thanks Kevin Riley for the translation. He would also like to thank LASMAS-Institut $d u$ Longitudinal (CNRS) and the Laboratoire de Sociologie Quantitative (CREST-INSEE) who have provided the survey data he has used and express his gratitude to Raymond Boudon, Louis Chauvel, John H. Goldthorpe, Michel Gollac, Dominique Merllié, Claude Thélot and his colleagues at the Revue Française de
Sociologie for their comments on the first draft of this paper. The models used have been estimated with the LEM software program (version 1.0 dating from 18 September 1997) developed by Jeroen $\mathrm{K}$. Vermunt (University of Tilburg). Readers may also refer to this author's book Log-linear Models for Event Histories (1997). During the year 1999, this article was presented in international conferences which were held in the University of Potsdam, the University of Wisconsin in Madison and the European University Institute in Florence. 


\section{Revue française de sociologie}

Is it possible to identify long-term temporal trends in the social mobility regime of modern societies? In the past this has been one of the most frequently debated issues amongst sociologists of stratification and mobility, and it remains so today. In 1927 Pitirim Sorokin answered this question in the negative when he expressed doubts about the possibility of discerning a secular trend in the change in mobility within a society: "In the field of vertical mobility [...] there seems to be no definite perpetual trend towards either an increase or a decrease of the intensiveness and generality of mobility. This is proposed as valid for the history of a country, for that of a large social body, and, finally, for the history of mankind." (1959, p. 152). This author nevertheless recognized that many trends could have existed over the course of history and that, in particular, in western societies the inheritance of occupations had decreased during the last century. However, over a long period, Sorokin saw waves of high mobility giving way to cycles of greater immobility and thus concluded that, in the very long term, the situation was one of "trendless fluctuation".

We can say that in many ways the continuation in contemporary sociology of Sorokin's theory, which referred to absolute mobility rates -that is to say observed mobility- is the more sophisticated concept of the temporal invariance of mobility regimes which was put forward in 1975 by Hauser, Koffel, Travis and Dickinson. This theory stated that the existence of significant temporal variations in observed mobility rates is merely the result of macrostructural changes -in particular changes in job distributions- which are independent of the fundamental structure of mobility, while relative mobility rates remain stable over time. In other terms, the changes in socio-occupational structure which occur over the generations mean that the chances people from a certain social origin have of reaching one or the other of two social destinations change over time; however, they remain unchanged when compared to the corresponding chances of people from another social origin. Phenotypical change in observed mobility therefore goes together with genotypical permanence in the level of statistical association between social origin and destination. This was what had been observed by Hauser et al. (1975) when they examined the available American data using log-linear modelling methods, which had newly been introduced into sociology by Goodman (1972). The same hypothesis was popularized in the work of Goldthorpe (1980) under the name constant social fluidity and has frequently, and often successfully, been tested by comparison with empirical data from a large number of countries, leading some authors to conclude that there is a high degree of inertia in intergenerational social mobility regimes (see for example Goldthorpe and Payne, 1986). The title of Erikson and Goldthorpe's comparative study of social mobility in industrial societies -The Constant Flux - has thus been marked by the temporal invariance theory. This leads to the supposition that a fixed level of inequality of opportunity exists within the structural core of modern societies.

"Trendless fluctuation" of absolute rates and temporal invariance of relative rates are not the only hypotheses which sociologists have put forward in connection with change in social mobility. In the same tradition as the work of 
Parsons (1951) and Kerr et al. (1960) on the functional requirements which are imposed by the industrialization process, North American social scientists have argued that we should anticipate a slow but continuous increase in the general level of social fluidity in modern societies. In The American Occupational Structure (1967, p. 429), Blau and Duncan state that, in the American economy, technological change has redefined occupational recruitment. According to these authors, industrial society is characterized by a fundamental trend towards increasing universalism, and objective evaluation criteria are gaining increasing universal acceptance. Blau and Duncan therefore expect that it will be less and less possible to inherit high status directly and that attaining it will increasingly have to be legitimated by the proof of specific personal skills. They therefore contend that modern societies are characterized by less ascription-i.e. that less importance and weight is given to aspects which are inherited from the family of origin- and by more achievement -with more importance and weight given to acquired status, primarily through education. Making inter-cohort comparisons on the basis of the 1962 survey Occupational Changes in a Generation in order to study the determinants of educational attainment and first job status, Blau and Duncan were however unable to detect any clear temporal trend. Three years later, Treiman (1970) also hypothesized the existence of a direct link between the level of economic development and social mobility and stated the theory of industrialism according to which the level of direct transfer of status from parents to children will tend to fall as a society becomes more industrial. According to this theory, the process of industrialization will lead to a transformation not only of economic institutions such as the structure of the labour market, but also social institutions such as the family and the education system. Directly or indirectly, industrialization will break down old barriers, open up new possibilities for social advancement and change the basis for the acquisition of status from one of ascription to one of achievement. Apart from the transformations in the socio-occupational distribution which it will require and the structural mobility which is associated with it, industrialization will make individual destinations less dependent on social origins and thereby lead to a gradual increase in the openness of the mobility regimes in societies. This theory has not only attracted the attention of sociologists, but also stimulated research by social historians during the last two decades (see in particular Kaelble, 1981; Miles and Vincent, 1993; Van Leeuwen and Maas, 1996).

\section{An international debate about temporal change in social fluidity}

In an ambitious study Ganzeboom, Luijkx and Treiman (1989) have reconsidered the question of cross-national and cross-temporal variations in intergenerational social mobility. For this purpose they used 149 mobility tables drawn from 35 nations, all but 5 of which were based on data for the period after 1955 and which all shared the same six-fold class schema. In order to describe, within each mobility table, the strength and the structure of the 
link between social origin and destination, the authors have used a general model derived from Goodman (1979) which represents this statistical association by means of three sets of parameters: two scales of estimated scores one of which relates to origin classes and the other to destination classes and a single parameter which measures the general strength of the intrinsic association between origin and destination. (1) Ganzeboom, Luijkx and Treiman conducted their study of societal and temporal variations in social fluidity in two stages. In the first, they selected two statistical models which measure differences in mobility regime in a parsimonious way. They thus estimated a general parameter for each table which expresses the strength of the link between the social class of the father and that of the son, and, if relevant, a second parameter which expresses the overall propensity for social inheritance. Considering each mobility table as an individual case, the authors then consider to what extent the variations in the above parameters depend on and can be explained by the country in question, the year in question, the differences in data quality and measurement errors.

Their analyses reveal that one fifth of the variance in the general association parameter is caused by differences in the quality of the data, but a further third is to be ascribed to the "country" variable. From this Ganzeboom et al. have deduced that although the general pattern of social fluidity is quite similar in different countries, its extent differs considerably. Finally, a small but significant percentage -between 2 and $3 \%$ - of the variance is due to the period in which the data were collected. All the authors' estimations agree on this and point to the conclusion that the strength of the link between social origin and destination is decreasing slowly but regularly at the rate of about one percent per year. Ganzeboom, Luijkx and Treiman make the following comment concerning their analysis: "This result provides strong support for the claim of a world wide secular trend toward increased societal openness [...]. The decrease in association is about one percent per year. Although this is a negligible amount in the short run (and therefore difficult to estimate over short periods), it implies very substantial change in the long run." (1989, pp. 44-45).

In order to confirm what these authors referred to as "our discovery of a world wide secular trend toward increased societal openness" (1989, p. 45), Ganzeboom et al. undertook separate analyses of the data for those countries for which they possessed at least three mobility tables of satisfactory quality. The result, for fifteen of the eighteen countries involved, was a negative coefficient, which corresponds to an almost general linear trend towards a reduc-

(1) This model, known as the "(quasi) log-multiplicative row and column effects model" includes, amongst other features, six diagonal parameters which express the intergenerational social immobility which is specific to each class. We shall give a more formal presentation in the last but one section of this paper where we shall use it on French data to confirm our results. See also Clogg and Shihadeh (1994) for a general description of this model (which does not require any a priori hypothesis about the order of classes in the social structure) and the manner in which it has been extended. 
tion in the statistical association between social origin and destination (2) and the authors have calculated that the probability of this result -or another even more extreme result- would be only three in a thousand under the null hypothesis of an absence of temporal change.

Although it drew the attention of the sociological community, the research conducted by Ganzeboom, Luijkx and Treiman was also criticized by a number of authors. First of all, Jones (1992) pointed out that they had failed to test the hypothesis that all 149 studied tables share a common social fluidity. By re-analyzing their data he showed that this hypothesis accounts for $95 \%$ of the statistical association explained by Ganzeboom et al.'s preferred model, the remaining $5 \%$ being the result of cross-national and cross-temporal variations in mobility regimes. In the light of this, Ganzeboom, Luijkx and Treiman's conclusion $(1989$, p. 48$)$ that "the hypothesis of common social fluidity is simply incorrect" would seem to be a clear exaggeration.

In the chapter which they devoted to trends in class mobility, Erikson and Goldthorpe also subjected this research to scrutiny (1992, pp. 99-101). They began by criticizing the fact that Ganzeboom, Luijkx and Treiman conducted a single analysis which ascribed equal importance to data which vary greatly in quality and robustness. For example, while for France Ganzeboom, Luijkx and Treiman used the 1964 and 1970 Formation - Qualification Professionnelle surveys, their mobility tables for 1958 and 1967 related to merely 335 and 743 individuals respectively. Erikson and Goldthorpe went on to expose an aspect in the results of the study conducted by Ganzeboom et al. which is somewhat at odds with their general conclusion: the fact that, while the reduction in the link between the social class of the father and that of the son is significant for the general association parameter, it is not for the overall propensity for social inheritance. A third criticism stressed the restrictive nature of the model favoured by these authors; because it estimates a single scale for both origin and destination classes it only fits a minority of all the mobility tables satisfactorily. Erikson and Goldthorpe, agreeing with the criticism of Jones, concluded by showing that if Ganzeboom, Luijkx and Treiman had complied fully with their model selection criteria they would in fact have favoured the hypothesis of cross-national and cross-temporal invariance of social fluidity.

Finally, Wong (1994) undertook a careful re-analysis of the same data, paying particular attention to those for the United States between 1947 and 1986, for England (1951-86) and Japan (1955-75). In contrast to the strategy adopted by Ganzeboom, Luijkx and Treiman, Wong systematically compared different versions of the same model: parameters were estimated with the hypothesis of temporal invariance, with the hypothesis of change of any type occurring between two dates, and finally with the hypothesis of a linear trend. The results bring into question the main conclusion reached by Ganzeboom

(2) This linear trend is, however, only significant in the case of nine or twelve countries (depending on which model is used).
France is one of these, using mobility tables collected in 1958, 1964, 1967 and 1970. 
et al.: the temporal change in social fluidity is frequently insignificant and difficult to demonstrate. In the case of the eighteen countries covered by the study, a progressive opening up of the intergenerational mobility regime can only be irrefutably established for Hungary and Sweden, being somewhat less certain for England, the United States, France and the Netherlands. For the other countries, the statistical analyses support the hypothesis that the mobility regime is extremely stable. Wong concludes by expressing doubts as to the existence of a universal trend toward increased societal openness and suggests that the explanation for temporal changes in social fluidity is to be found in national historical contexts.

In order to test the predictions made by the "liberal theory of industrialism" -to use the term these authors themselves apply- Erikson and Goldthorpe (1992, pp. 86-96) use a methodology which is very different from that of Ganzeboom, Luijkx and Treiman. Having at their disposition, for nine European countries, a representative national survey conducted in the first half of the seventies whose data had been recoded into a homogeneous class schema, they analyzed trends in social mobility by comparing the experience of men belonging to four birth-cohorts, i.e. who were aged from 25-34, 35-44, 45-54 and 55-64 at the time of the survey. Erikson and Goldthorpe estimated, initially, a log-linear model which postulates identical relative mobility rates for different cohorts. In eight of the nine countries such a model accounted for more than $90 \%$ of the total association existing between class of origin and class of destination, and in none of these countries did it lead to the misclassification of more than $5 \%$ of the total data-set. These results support the hypothesis of the temporal stability of mobility regimes; as these authors state, they in fact suggest that if there have been changes in societal openness they have in no case been substantial. Erikson and Goldthorpe nevertheless recognized immediately that such an empirical test is not entirely satisfactory: "[The test we conducted] is one of a very generalized or 'global' kind -with, therefore, only a low power to detect shifts that may have taken place in more particular aspects of mobility regimes. That is to say, even where the hypothesis as represented by the constant social fluidity model cannot be safely rejected, the possibility still remains that certain changes over cohorts could have occurred which, while on an overall view quite small, might none the less be of substantive interest. And, in this connection, we must clearly recognize that the liberal theory claims not simply that fluidity patterns change, but that they do so in a particular direction, namely, towards increased fluidity. Thus, if we are to do full justice to this theory, we need to test as specifically as we can for trends of the kind in question." (1992, pp. 90-91).

To this end, Erikson and Goldthorpe have made two modifications to the temporal invariance model. The first consists of assuming that the general pattern of social fluidity is stable over time, but that its extent varies systematically from one cohort to another. If one birth-cohort is taken as a reference, estimating, for each of the others, an additional parameter expresses the fact that its mobility regime is uniformly nearer (or further) from the equality of 
opportunity which is represented by the complete absence of association between class of origin and class of destination. (3) Erikson and Goldthorpe's second modification involves immobility. It consists of postulating that the mobility regime is stable, but that there is intrinsic variation for all classes in the tendency to "inherit" one's father's position. In this context, the general theory of industrialism would lead one to expect an increase in the general level of social fluidity and/or a decrease in the chances of social immobility as one moves from the oldest to the youngest birth-cohorts.

The extreme result where both the envisaged modifications improve the fit and express a monotonic change (in the increase in the general level of social fluidity and also in the weakening of the chances of immobility) does not occur in any of the investigated countries. Hungarian society is that which is the closest to this situation with a steady trend towards greater equality of social opportunity in the case of the three oldest cohorts but not the youngest. In three other countries, the uniform difference model is significantly closer to the data than the temporal invariance model. However, the estimated parameters for the Federal Republic of Germany and Sweden show no regular temporal variation, and those for France reveal a tendency for social fluidity to diminish as one moves from the oldest to the youngest cohorts. ${ }^{(4)}$ In the five remaining countries, in addition to the fact that none of the modifications made to the temporal invariance model is significant, the estimated parameters do not suggest that there is a notable shift towards greater societal openness. Erikson and Goldthorpe therefore end their analysis in support of the stability of temporal mobility regimes rather than their variation as predicted by the liberal theory: "We do have evidence that a considerable degree of stability in relative rates has underlain the mobility experience of men in successive birth-cohorts within our nine nations; and the contrast may be underlined between the rather slight nature of such shifts as we are able to detect in relative rates and the much larger and more rapid changes that we could often trace in absolute, total and outflow, rates." (1992, p. 96). Finally, by engaging in a global analysis combining the data from the nine countries, Erikson and Goldthorpe show that the variation in mobility regimes between different cohorts has been considerably less than the differences in social fluidity between the different societies in question.

(3) This is the origin of the name "log-multiplicative model of uniform difference" or UNIDIFF which Erikson and Goldthorpe give to this statistical representation. The same model was also put forward, independently, by Xie (1992). We shall give a more formalized description later in this paper where we shall use it to analyze French data.

(4) The authors nevertheless note that this result conflicts with earlier research based on the same 1970 survey and previous data from 1953, which showed a weakening of social immobility in French society (Goldthorpe and Portocarero, 1981). Erikson and Goldthorpe explain this divergence by stressing that this research covered a much longer period and included older male generations. It is also true that a shortcoming of the methodology used in their book is that it confuses the effects of generation and life cycle (or career cycle) as it compares the experience of men who, while belonging to different generations, are also observed at different stages of their occupational life. 
A gradual tendency towards greater class equality has also been detected by national studies in certain countries which have already been mentioned. As early as 1983, Erikson demonstrated a gradual increase in the openness of Swedish society and this finding has been confirmed more recently by the use of more sophisticated models (Jonsson and Mills, 1993). A similar tendency has been described for the Netherlands between 1954 and 1977 (Ganzeboom and De Graaf, 1984) and also between 1970 and 1985 (Luijkx and Ganzeboom, 1989). (5) It is also well documented in the case of Hungary (see in particular Ganzeboom, Luijkx and Róbert, 1989; Wong and Hauser, 1992). The United States merits special attention. Three years after Hauser hypothesized the temporal invariance of the intergenerational mobility regime, his "initial presumption" had to be "modified substantially" (Featherman and Hauser, 1978, p. 137) on the basis of a comparison between the 1973 survey Occupational Changes in a Generation and the data collected eleven years previously by Blau and Duncan. Their analysis revealed a number of changes which led Featherman and Hauser to conclude that an increase in the relative chances of intergenerational mobility had taken place. ${ }^{(6)}$ Later, Hout (1984) confirmed that independently of structural changes in American society, the statistical association between the status of the father and that of the son -measured using Duncan's Socio-Economic Index- had decreased on average by $28 \%$ between 1962 and 1973 . The same author extended his analysis to cover a more recent period using data from the General Social Surveys conducted between 1972 and 1985 (Hout, 1988). In the case of both men and women he again observed that the statistical association between social origin and destination had weakened, to a similar extent as during the previous period. By introducing educational attainment as an intermediate variable, Hout $(1984,1988)$ was finally able to shed light on the driving forces behind this gradual opening up of the American mobility regime. Firstly, the link between the social destination and origin of individuals without a University degree became less strong during the period. Furthermore, social destination was independent of social origin in the case of those with a University degree, and the relative number of such persons increased between 1962 and 1973 and also between 1972 and 1985. The gradual increase in social fluidity in American society is thus partly due to the effects of its composition: among the working population there has been an increase in the proportion of the most highly qualified groups for whom the statistical association between social origin and destination is the lowest.

In the chapters which they devoted to three non-European countries -Australia, the United States and Japan-, Erikson and Goldthorpe (1992, pp. 325-326) re-examined, using their class schema, the data collected by Featherman and Hauser as well as those used by Hout. While recognizing that there may well have been a trend towards greater equality in social opportu-

(5) For a confirmation of this finding see also Erikson and Goldthorpe (op. cit., p. 172).

(6) Cherkaoui (1992, pp. 180-182) has already stressed this point in his account of the survey which Featherman and Hauser conducted in order to reproduce that carried out by Blau and Duncan eleven years earlier. 
nity in the United States, they argued, however, that from a statistical point of view such a change can only have been slight. For example, in the case of the birth-cohorts in the 1973 survey the fit of the uniform difference model was not significantly better than that of the constant social fluidity model. Moreover, in Hout's model the weakening of the link between social origin and destination only involved the dimension of status, whereas an opposing trend seems to be apparent for the other dimension of work autonomy which is extremely important in the context of class analysis.

\section{French society: Almost constant social fluidity?}

In France, there is wide acceptance among sociologists that social mobility has greatly increased in recent decades, as a result of structural changes which have taken place in society, but that the inequality of social opportunity -or the structure of mobility - has remained virtually unchanged. This conclusion has become widely accepted since the publication in 1973 of Raymond Boudon's important work: L'inégalité des chances. La mobilité sociale dans les sociétés industrielles. Observing that in Western societies there had been a reduction in inequality of educational opportunities but that the resultant social mobility seemed affected by only slight and erratic variations, Boudon developed a formal model for the allocation of social positions on the basis of class of origin and educational attainment, and examined the consequences which a process of educational democratization would have on such a system. ${ }^{(7)}$ His main conclusion was that a reduction in the inequality of educational opportunities is not incompatible with the stable mobility structure revealed by the available data. The mismatch between the educational structure and the social structure, the fact that the latter changes much more slowly than the former, the queuing process produced by a reduction in social expectations associated with low and moderate levels of education, the possible presence of an effect of dominance which, at a given level of educational attainment, will tend to award the best social destinations to individuals with the highest origins, all act in favour of this result: "In general, the considerable increase in school attendance rates and the democratization of education do not mean that mobility will necessarily increase or its structure change over time. The model leads to minor oscillations in mobility rather than unidirectional changes. This theoretical result, like those which preceded, is compatible with observations." (Boudon, 1978 [1973], p. 215; see also Boudon, 1974, p. 196).

In a recent paper on French data from 1982 and 1994 for men in the labour force aged between 42 and 54, Forsé (1997) re-examined Boudon's theory

(7) See, in particular, Chapters 6 (Esquisse d'une théorie formelle de la mobilité sociale) and 7 (Données sur la mobilité sociale et son évolution). Readers may also refer to the
English version of the book: Education, Opportunity, and Social Inequality. Changing Prospects in Western Society (1974). 
from an empirical viewpoint. He concluded that his analysis generally confirmed the theory: while for comparable populations over the twelve year period the average level of education had risen and there had been a slight reduction in the inequality of educational opportunity with respect to social origin, the "net diagonality index" (Forsé and Chauvel, 1995) of the mobility tables did not vary significantly, and the author concluded that in French society "social fluidity is almost constant" (p. 234). The same diagnosis had already been made by Gollac and Laulhé (1987) who adapted 1985 sociooccupational distributions to a 1977 mobility table; they compared the result to the actual data for 1985 and found only minute changes in the mobility regime. ${ }^{(8)}$ Merllié and Prévot (1997, pp. 56-58) applied the same method to analyze the link between social origin and destination between 1977 and 1985 and between 1985 and 1993. Their study revealed that "the changes are small, and in different directions for different categories and do not allow us to conclude that significant change has taken place". Finally, Goux and Maurin (1997a, 1997b) have used the potential of log-linear modelling to analyze the forms of the status attainment process, i.e. the links between social origin, educational attainment, position on initial entry into work, subsequent position, and any changes which might have occurred in these between 1977 and 1993 (in some cases 1970 and 1993). One of their most important findings relates to the temporal stability of these links: "Educational and social inequalities seem neither stronger nor weaker today than one or two decades ago. Perhaps other class schemata (or statistical techniques) might have led to slightly different estimates and evaluations. These results can nevertheless serve as an initial approximation." (1997a, p. 25). The authors reached this conclusion on the basis of two observations: firstly, whichever aspect of the status attainment process is examined, a statistical model which postulates that the fundamental relationships ${ }^{(9)}$ remain unchanged over time is able to reconstruct French survey data accurately; secondly, when a temporal interaction of this type is introduced it fails to achieve statistical significance in a global test. ${ }^{(10)}$

The latest studies have therefore concluded that in France the inequality of social opportunity has remained stable over recent decades. This paper will argue that this conclusion should be questioned and examined more closely for reasons of two different types. The first is methodological. It is obviously

(8) See, in Gollac and Laulhe's paper, the box entitled "1977-1985: little change in destinations" (p. 89). The technique they use is an iterative proportional fitting algorithm (the RAS or Deming-Stephan algorithm) which retains the odds ratios in the initial table while modifying the margins (see Vallet, 1986, p. 673 for a fuller description of this). This procedure amounts to estimating a log-linear model where there is no interaction between origin, destination and time and which therefore expresses the constant social fluidity hypothesis.
(9) For example, the association between social origin and educational attainment, between educational attainment and social destination, or between social origin and destination.

(10) By which is meant a test which uses all the parameters which relate to the interaction between the three variables in question. For example, in the case where three dates and six origin and destination categories are considered a test of this type uses $(3-1)(6-1)(6-1)=50$ degrees of freedom. 
the case that the mobility regime of a society is a structural characteristic which, if it changes at all, does so extremely slowly over a long period of time and a number of generations. By its nature, this -hypothetical- change is therefore difficult to observe. Its analysis therefore requires statistically powerful models, i.e. models which detect temporal change in a limited number of parameters. This is the reason for Erikson and Goldthorpe's comment (1992, pp. 90-91), which is quoted above, and also their introduction of the uniform difference model and the model which postulates a change in the chances of immobility, as improvements on the constant social fluidity model. This characteristic is also shared by all the studies from abroad presented in the first part of this paper. However, the research we have just mentioned concerning France all bases its conclusions on use of the temporal invariance model or an equivalent. (11) The fact that the answer the authors reach seems to substantiate invariance should perhaps not be interpreted as meaning that there is no variation as regards such and such a specific aspect of social fluidity, but might also express the inability of the modelling used to detect a change of this type, if one exists.

There is another reason for re-analyzing temporal trends in social fluidity in French society: while, as we have said, many studies come down in favour of stability, all do not. In his analysis of the social destinations of men in the workforce aged between 40 and 59, Claude Thélot (1982) showed that there had been a considerable increase in observed mobility in the third quarter of the century. In an eight-group class schema, $50.5 \%$ of men were placed in the same group as their father in 1953, but only $37.8 \%$ were in 1977 . Most of this change resulted from the fact that the changes in French society over the twenty-four year period had increased the difference between the social structure of fathers and sons. However, all the change could not be explained in this way. Showing that about one quarter of the reduction in intergenerational social immobility was due to a weakening of the "pure" tendency towards social inheritance, the author drew the conclusion that there was increased openness in the mobility regime: "In the framework of this analysis we can state that French society has become slightly more flexible: from one generation to the next, all things being equal, the tendency towards social inheritance has diminished in most social groups." (1982, p. 79). This conclusion has also been confirmed by Goldthorpe and Portocarero (1981) and is also compatible with the results obtained by Ganzeboom, Luijkx and Treiman (1989) or Wong (1994) as regards France. Lastly, for the same period, it has also been shown that the chances of social immobility among women also underwent a comparable reduction both with respect to occupation (father-daughter tables) and marriage (father-husband tables) (Vallet, 1991, 1992). (12)

(11) In this respect, Forsé's most recent research constitutes an exception: the "net diagonality index" which the author uses falls very slightly, but not significantly, over twelve years (from 0.73 to 0.72 ).

(12) A slight increase in the openness of the social mobility regime in France has not only been revealed during the thirty year boom following the second World War. Fukumoto and Grusky (1993) have reanalyzed the body of data constructed by the American historian William H. Sewell Jr (1985) from marriage 
Therefore, what we must investigate is the extent to which the increasing openness of the mobility regime of French society that has been shown to have taken place during the third quarter of the century, marked by the economic expansion of which everyone is aware, has continued or been interrupted during the subsequent period. Here too, while most research points to a halt in this process there is no unanimity: applying the log-multiplicative uniform difference model to French data for the period between 1970 and 1985, Goldthorpe (1995, pp. 68-69) has detected signs of a slow increase in the general level of social fluidity during the period in question. (13)

Thus, the remaining part of this paper will consist of an attempt to re-evaluate temporal trends in intergenerational mobility in French society. Three new features will distinguish this attempt from previous research. Firstly, our analysis will cover a period of forty years from the beginning of the fifties to the start of the nineties. In the area of social mobility, France is, with Hungary, one of the few countries where statistical data are available which are highly homogeneous, numerous, of good quality and regularly spaced in time. Secondly, the mobility experience of both men and women will be analyzed in order to arrive at a more confident evaluation of temporal trends. Finally, this study will make use of the analysis techniques which are currently used in this field, in particular the log-multiplicative uniform difference model and Goodman's log-multiplicative scaled association model. We shall begin by taking an example in order to explain the conceptual distinction between observed mobility and social fluidity and then describe the data and class schema which we shall use. This will allow us to construct mobility tables (showing destinations and origins) for the forty year period and thereby observe the modifications in the absolute rates of intergenerational mobility. A straightforward procedure -based on an examination of successive pairs of mobility tables for both men and women-will allow us to demonstrate that the general level of social fluidity increased continuously in France from the beginning of the 1950s to the beginning of the 1990s. The existence of the steady trend will be confirmed by applying a number of different models which take in, in a single sweep, the whole of the period in question. In the

registers in Marseille in 1821-22, 1846-51 and 1869. For this city, the first mobility table (1821-22) coincided with the end of the pre-industrial epoch, the second (1846-51) took place after the start of industrialization, and the third (1869) took place at the height of the "trade revolution". Fukumoto and Grusky demonstrate the existence of a small but regular downward trend in the chances of immobility (-10\% during the first transition, $-14 \%$ during the second) and a reduction in the general level of statistical association between social origins and destinations ( $-7 \%$ and $-9 \%$ respectively). We must stress once again that such changes can only be revealed if sufficiently sophisti- cated analysis techniques are used; as these authors state: "What must be immediately noted, however, is that the model of constant social fluidity is a rather blunt instrument with which to detect changes in the underlying mobility regime. If we wish to carry out a more powerful test of the null hypothesis, we must first devise models that can account for the origin-by-destination association in a parsimonious fashion." (1993, p. 47).

(13) The log-multiplicative parameter has been fixed at 0 for the 1970 mobility table and estimated at -0.06 for the 1985 table. This difference is significant at the one percent level. 
conclusion we shall discuss the significance of these results for French society and within the context of the international debate on the changes in the mobility regimes of societies. The paper will end by explaining how this research could be continued in order to show the driving forces which lie behind the long-term trend which has been revealed.

\section{Observed mobility and social fluidity versus structural mobility and net mobility}

The study of intergenerational social mobility and its temporal change have for a long time rested on the conceptual distinction between structural mobility (or "forced" mobility) and net mobility (or "pure", exchange or circulation mobility). This distinction involves considering the total, observed, mobility in a society at a given instant as the sum of two components, one of which (structural mobility) is seen as stemming solely from the change in social structure which has taken place over time (between the generation of fathers and that of their sons) and the other (net mobility) provides a measure of the degree of social fluidity or the intrinsic openness of the society in question. On the basis of this distinction, a measure of net mobility is obtained by subtracting the mobility resulting from structural change from the total mobility. The mobility resulting from structural change is evaluated on the basis of the dissimilarity between the socio-occupational distribution of fathers and sons as it appears in the margins of the mobility table (for more detailed description and presentation see Bertaux, 1969; Cuin, 1993, pp. 124-128 and pp. 230-233).

This conceptual distinction and its application in fact create more problems than they solve and have generally fallen into disuse in the last twenty years. ${ }^{(14)}$ Firstly, they are flawed in that what is of prime interest to the sociologist (net mobility) is measured as a residue. More fundamentally, a bias has been demonstrated in the evaluation of structural mobility. A number of demographic phenomena (differential marriage and fertility rates in the "generation" of the fathers, differential mortality in that of the sons, and migration) mean that the distribution of sons on the basis of their social origin is, in a strict sense, not representative of any actual social structure of the past. This observation, which in the English-speaking world is considered to date from Duncan's response (1966) to Kahl, had, actually, already been formulated as early as 1950 in France by Brésard. Finally, Goldthorpe (1980) has emphasized the internal contradiction which exists between the conceptual distinction and its implementation: although it is only possible to distinguish empirically between structural mobility and net mobility on the basis of individual movements which are observable in a table, these concepts are only significant at a supra-individual or macro-sociological level.

(14) See, however, Luijkx (1994) for a survey of more recent attempts to apply the same distinction. 
From the end of the 1970s this distinction was replaced by the distinction between observed mobility (or absolute mobility rates) and social fluidity (or relative mobility rates). By so doing, sociologists of stratification were able to retain the essence of the aforementioned paradigm while avoiding the pitfalls. The new distinction abandoned the questionable idea that there are two types of mobility and essentially consists of recognizing that social mobility phenomena can be -or perhaps should be- studied from two differing but complementary points of view.

The absolute mobility rates approach (also known as the observed mobility approach) consists of analyzing social mobility in its historical context as it is affected by intergenerational changes in socio-occupational distributions. Calculating the total amount of immobility and examining destinations and origins are techniques which are used in order to investigate this most visible part of mobility, which is also the nearest to the conscious experience which individuals have of mobility.

On the other hand, the social fluidity -or relative mobility rates-viewpoint consists of investigating the structure and strength of the association between social origin and destination independently of the socio-occupational distribution of fathers and of sons. This "in-depth" approach to mobility tables makes use of a measure of association which has this property of independence with respect to marginal distributions -the odds ratio- and also uses a statistical technique (log-linear modelling) which allows us to formulate and test hypotheses about the odds ratios. (15) Rather than maintaining that total mobility is the sum of the net mobility and the structural mobility, the new conceptual distinction sees the problems of mobility in the following terms: at a given instant, an intrinsic mobility or social fluidity regime combines with the socio-occupational distributions of fathers and of sons which are specific to this historical moment and thereby generates the observed mobility which applies at that moment in that society.

Observed mobility and social fluidity therefore constitute two distinct but complementary approaches. The mobility tables for a given society at two different dates - or for men and for women in the same society, or for two different societies- can differ when considered from the point of view of observed mobility while appearing similar from the point of view of social fluidity. In this situation the same "body" -the mobility regime- in a manner of speaking wears different clothes because the social structure has changed over time, or because the socio-occupational distribution is different for the two sexes or alternatively because the societies in question have reached different levels of development and have had different histories. In more statistical terms, two contingency tables may exhibit the same association between variables but different margins.

(15) A description of the use of log-linear modelling for the comparative analysis of survey data is to be found in Cautrès (1997). 
Let us take the fictional example of a society with just two social positions -professional and worker- in which the intergenerational mobility has been observed at two dates separated by a period of tertiary sector growth with the percentage of available professional-level social positions rising from $25 \%$ to $35 \%$.

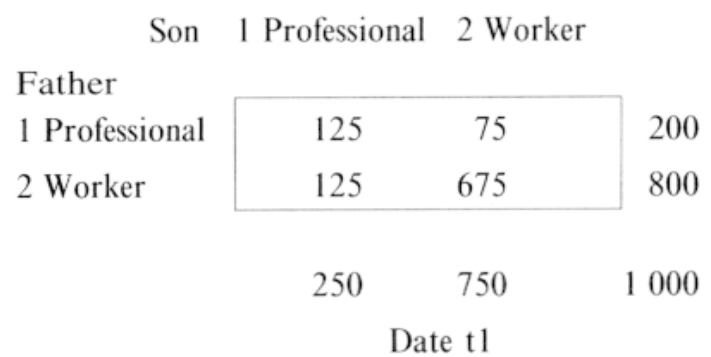

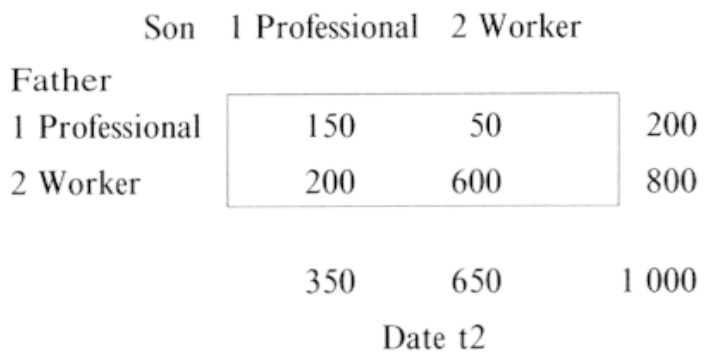

In this society, observed mobility has increased over time. At date $t 2$, one quarter of the men in the survey are not in the same social class as their father, whereas this applied to only $20 \%$ at date $t 1$. Similarly, the chances of the son of a worker attaining the position of professional have increased from $15.6 \%$ in $\mathrm{t} 1$ to $25 \%$ in $\mathrm{t} 2$. Among the sons of professionals, it has also become more common to maintain the same social position $-75 \%$ in $\mathrm{t} 2$ compared to $62.5 \%$ previously. These changes all seem to be associated with tertiary sector growth which has increased the chances of access to a professional position and also increased the dissimilarity between the socio-occupational distribution of sons and that of their fathers.

Does this mean that in relative terms the inequality of sons of professionals and the sons of workers as regards access to one position rather than the other has changed over time? The odds ratio takes the form:

$$
\frac{\left(n_{11} / n_{12}\right)}{\left(n_{21} / n_{22}\right)} \text { or } \frac{\left(n_{11} / n_{21}\right)}{\left(n_{12} / n_{22}\right)} \text {, or } \frac{\left(n_{11} n_{22}\right)}{\left(n_{12} n_{21}\right)}
$$

and the first of these expresses the result of competition between individuals from the two social origins to reach the first as opposed to the second of the two possible destinations (Goldthorpe, 1980). The closer this value is to 1 the fairer the competition, or the more perfect the mobility. For our fictional society it is easy to calculate that there has been no change in this value between $\mathrm{t} 1$ and $\mathrm{t} 2$ :

$$
\frac{(125 / 75)}{(125 / 675)}=\frac{(150 / 50)}{(200 / 600)}=9
$$

Thus at date $t 2$ as at date $t 1$ the odds of becoming a professional rather than a worker are still nine times greater for the son of a professional than for the son of a worker. When measured by the odds ratio, the distance between the two social origins with reference to acquiring one or other of the two social destinations has remained unchanged, or put in other terms the "pure" associa- 
tion between social origin and destination has not weakened between $\mathrm{tl}$ and t2. (16)

In the society in question, observed mobility has therefore increased but social fluidity has remained constant. There is no contradiction in this. The change in observed mobility is the result of any change in social fluidity and any general change in society which is reflected in an approximate way by marginal distributions, and which may take place at varying rates depending on the moment in history. In our fictional society the increase in observed mobility is caused solely by the difference between the socio-occupational distribution of the sons and the fathers which increased between $t 1$ and $t 2$, and expresses no tendency towards a more open mobility regime. The central question which this paper aims to resolve is whether French society has undergone a development which is similar to that of our fictional society, as has been concluded by several recent studies.

\section{Forty years of social mobility in France: the available data}

We are unable to use the survey carried out in 1948 by the Institut National d'Études Démographiques in order to study intergenerational mobility change over half a century; it considered the association between fertility and social mobility but the sample it used was not intended to be representative at national level. However, we can use the June 1953 Enquête sur l'emploi as Jacques Desabie $(1954,1955)$ added three extra questions to it, one of which was "When you left school what was the occupation of your father (or mother or guardian)?" The individual data from this survey are no longer available, all that remains is the results in the form of tables. Separate mobility tables have been drawn up for men and women, for ten year age groups. They do not permit us to distinguish between French nationals and foreigners or to identify those members of the workforce who are unemployed. For our analysis we have selected men and women in the workforce aged between 30 and 59 at the time the survey was conducted. The corresponding mobility tables are for 3,483 men and 2,007 women. (17)

(16) The odds ratio varies between 0 and $+\infty$, and takes on a value of one in a situation of statistical independence (where there is no link between social origin and destination). Use of the natural logarithm restores the symmetry of the measurement: Log (odds ratio) is between $-\infty$ and $+\infty$. Readers may refer to Vallet (1988, p. 400 , note 8 ) for a demonstration that the odds ratio measures the statistical association inside the contingency table, i.e. independently of marginal distributions. In a mobility table with NI rows and NJ columns a set of
(NI-1)(NJ-1) independent odds ratios is sufficient to describe the statistical association between origin and destination. Finally, the hypothesis of the invariance of social fluidity can be represented by the log-linear model of absence of interaction between origin, destination and time: this assumes that the association (measured using odds ratios) between two variables (origin and destination) is constant as the third variable (time) changes.

(17) These tables are to be found in Vallet (1991, p. A40). 
The Formation - Qualification Professionnelle survey conducted by the Institut National de la Statistique et des Études Économiques in 1964 cannot be used either: only individuals of less than 47 years of age stated their father's occupation. We are, however, able to use the four subsequent surveys in the series which date from 1970, 1977, 1985 and 1993. At each of these dates the principal indicator of social origin was constructed on the basis of the same question, supplemented by others of a more precise nature: "What was the occupation of your father (or guardian) at the time you ceased attending school or university on a regular basis?" For analysis we have selected all working French persons aged between 35 and 59 years in the survey year. The sample sizes were as follows: for men 10,011 in $1970 ; 9,407$ in $1977 ; 8,827$ in 1985 and 4,013 in 1993 and for women -in the same order- 3,561; 4,556; 5,178 and 3,182 . (18)

Thus, for a period of forty years five mobility tables are available which compare the occupation of sons with that of their fathers at an equivalent age $(\mathrm{N}=35,741)$ and similar tables for women also exist $(\mathrm{N}=18,484)$. (19) The highly homogeneous nature of these data which all originate from the same series of surveys provides us with an optimum situation for studying temporal trends. Only the 1953 survey might suffer from slight comparability problems (Thélot, 1983), so care should be taken that our conclusions do not rely too heavily on this survey. Table I summarizes the period covered by our analysis. Depending on their dates of birth and the ages at which they finished their education, those persons in the generations observed in the earliest mobility table left the educational system and entered the employment market between the first decade of the century and just after the second World War. In contrast, the generations covered by the most recent mobility table began working between this immediate post-war period and the start of the eighties. Table I also shows that the thirty generations studied in 1953 cannot be observed any more as they had been completely replaced by the time of the 1985 survey. Similarly, almost all the generations in the 1970 survey had been replaced by 1993. It is clear that this situation is likely to reveal any long-term trends, even minor.

However, there is a real difficulty as regards the class schema for such a long period. The tables in the 1953 Enquête sur l'emploi used a grouping of what is known as the Catégories socioprofessionnelles (CSP) classification which was to be adopted from the following year for population censuses and official surveys. This is the eight-class schema which we shall use (Table II) and which can also be used without difficulty for the 1970 and 1977 surveys. This grouping has already been used by Thélot (1982) and is also quite close

(18) These samples are representative of $5,712,000$ men and $3,397,000$ women in 1970 ; $5,971,000$ and $3,700,000$ in $1977 ; 6,139,000$ and $4,404,000$ in $1985 ; 6,937,000$ and $5,399,000$ in 1993 .

(19) The response rate for the 1953 survey is unknown to us; it was $87.8 \%$ in 1970;
$86.9 \%$ in $1977 ; 87.8 \%$ in 1985 and $88.3 \%$ in 1993. In the case of these last four surveys the analyzed data have been corrected to allow for nonresponses. It is therefore unlikely that our analyses have been affected by systematic bias in the quality of the surveys. 


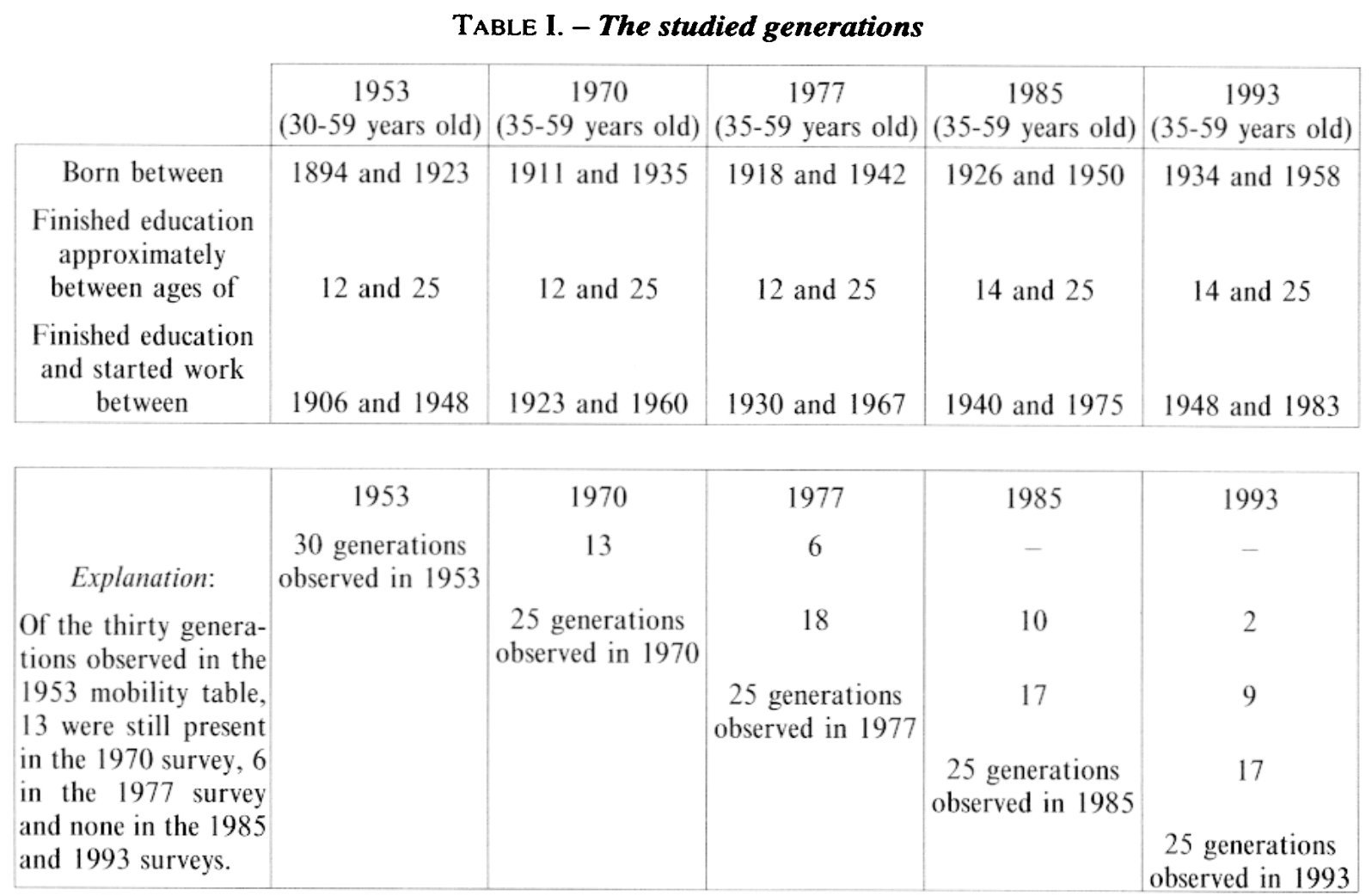

to that used by Erikson, Goldthorpe and Portocarero (1979) in their first comparative studies of France, England and Sweden. The change to a new schema known as Professions et catégories socioprofessionnelles (PCS), which occurred in 1982, means that the uniformity of coding was broken for the 1985 and 1993 surveys. We therefore decided to use the two-digit version of this new classification in order to reconstruct categories which are as close as possible to those of 1953, 1970 and 1977. The correspondence achieved in this way is only approximate, as strictly speaking it is not possible to transpose a $P C S$ into a $C S P$, or vice versa (Seys, 1984). We can however hope that the equivalence we have established distorts observed mobility events to only a minor degree and therefore has little negative impact on our long-term temporal study. Furthermore, the data from the 1977 Formation - Qualification Professionnelle survey were subsequently recoded to the PCS schema, which provides a means of connecting the series and evaluating more accurately any bias which affects long-term analysis as a result of changes in statistical practices. Using our eight-class schema of social origins and destinations we are first of all able to observe changes in absolute mobility rates. 
TABLE II. - An eight-class schema of social origins and destinations

\begin{tabular}{|c|c|c|}
\hline & 1953,1970 and 1977 surveys & 1977, 1985 and 1993 surveys \\
\hline 1. & Farmers and smallholders (CSP OO) & Farmers and smallholders (PCS 11, 12, 13) \\
\hline 2. & Farm workers (CSP 10) & Farm workers (PCS 69) \\
\hline 3. & $\begin{array}{l}\text { Artisans, small shopkeepers, self-employed } \\
\text { fishermen (CSP 22, 23, 27) }\end{array}$ & $\begin{array}{l}\text { Artisans, shopkeepers and assimilated } \\
\text { occupations (PCS 21, 22) }\end{array}$ \\
\hline 4. & $\begin{array}{l}\text { Heads of undertakings, large shopkeepers, } \\
\text { liberal professions (CSP 21, 26, 30) }\end{array}$ & $\begin{array}{l}\text { Heads of undertakings with ten or more } \\
\text { employees, liberal professions (PCS 23, } \\
\text { 31) }\end{array}$ \\
\hline 5. & $\begin{array}{l}\text { Higher-grade professionals (CSP } 32,33 \text {, } \\
34)\end{array}$ & $\begin{array}{l}\text { Professionals and higher-grade intellectual } \\
\text { professions (PCS } 33 \text { to } 38)\end{array}$ \\
\hline 6. & Middle-grade professionals (CSP 41 to 44 ) & $\begin{array}{l}\text { Intermediate professions (except for super- } \\
\text { visors of manual workers) (PCS } 42 \text { to } 47 \text { ) }\end{array}$ \\
\hline 7. & $\begin{array}{l}\text { Non-manual workers, service workers, } \\
\text { other employees (CSP 51,53, } 70 \text { to } 72 \text {, } \\
80 \text { to } 82 \text { ) }\end{array}$ & Non-manual workers (PCS 52 to 56) \\
\hline 8. & $\begin{array}{l}\text { Supervisors of manual workers and manual } \\
\text { workers (CSP } 60 \text { to } 68)\end{array}$ & $\begin{array}{l}\text { Supervisors of manual workers, manual } \\
\text { workers (PCS } 48,62 \text { to } 68)\end{array}$ \\
\hline
\end{tabular}

\section{France 1953-1993: Increasing observed mobility}

In the age group which interests us, in $195350.7 \%$ of men were placed in the same social class as their father. This high level of immobility fell steadily during subsequent decades, the figure being $40.0 \%$ in $1970,37.6 \%$ in 1977 (40.2\% at the same date in the PCS version of our schema), $36.5 \%$ in 1985 , and lastly $35.1 \%$ in 1993 . If the social position which women attain through their employment is compared to that of their fathers the change is even more marked. The total percentage of immobility for women was $47.6 \%$ in 1953 , $36.2 \%$ in $1970,30.5 \%$ in 1977 (30.7\% in the PCS version), $23.9 \%$ in 1985 and $22.9 \%$ in 1993.

So, in the middle part of the century only one man or woman in two had, on reaching adulthood, left their class of origin through their employment position. This was the case for approximately two out of three men and three out of four women at the start of the 1990s. This considerable increase in observed mobility is related to the profound transformations which have taken place in France over a period of forty years. On the one hand, the transition from a society with a large agricultural sector to an industrial society and then to a post-industrial society has resulted in large differences in the sizes of social classes between the generation of fathers and that of their children, and the greater these differences the greater the probability that social mobility will be high. ${ }^{(20)}$ On the other hand, as industrialization takes place in a soci-

(20) The dissimilarity between the socio-occupational distribution of sons (or daughters) and that of fathers can be assessed by the index of dissimilarity between the margins of the mobility table. For men, this takes on a value of $14.1 \%$ in $1953,21.3 \%$ in $1970,22.4 \%$ in $1977(22.8 \%$ in the PCS version of our class schema), $19.1 \%$ in 1985 and $20.9 \%$ in 1993. For women the corresponding values are $22.1 \%, 27.9 \%, 33.3 \%$ 
ety and the peasantry and the self-employed petty bourgeoisie account for a smaller proportion of the population there is a resultant increase in observed mobility because these two classes are characterized by a high degree of intergenerational immobility (Kurz and Müller, 1987).

Table III and Table IV show the change over forty years in the occupational destinations of men and women with different social origins. The 1977 survey data are given in two forms, corresponding to the two versions of our classs schema. By providing a link between the two series they also allow us to perceive the differences which result from changes in statistical coding: these affect mainly the separation between the self-employed owning small and large firms -classes 3 and 4 in our schema- and also, to a lesser degree, the split between non-manual workers on the one hand and manual workers and their supervisors on the other. In spite of these variations, the change in social destinations over the four decades is usually still quite marked and visible. (21) In what follows we shall comment on only a few of the most striking aspects.

While many changes affect both men and women with origins in the same social groups and would therefore seem to be the result of a general change in socio-occupational distributions, this is not true for them all. For men, remaining in the same social class as their fathers has become less frequent over our forty year period in the case of six of the eight social classes we have identified, the two exceptions being the sons of higher-grade and middlegrade professionals. Among women, these categories are joined by the self-employed with large firms, where change seems to be irregular, and by non-manual workers. In the case of the group of farmers and smallholders and the group of farm workers the number of children belonging to the same social group fell considerably. The reduction in immobility which had ceased among the sons of artisans and small proprietors at the end of the 1970s however continued among women from the same class, this difference between the sexes being no doubt due to the gradual fall in the percentage of women working as domestic helps. Although less marked, the reduction in social immobility was also regular until the mid-1980s among the sons and daughters of manual workers and their supervisors, these belong more frequently than in the past to the categories of higher-grade and middle-grade professionals (re-

(39.4\% in the PCS version), $46.5 \%$ and $47.6 \%$. The source of the increase in observed mobility is the growing difference (which seems to be levelling out at the moment) between the occupational structures of the two generations. It has been noted that in 1977 the change from CsP to PCS can lead to non-negligible differences in the total proportion of immobility or the index of dissimilarity between margins: at that date $18.4 \%$ of men and $16.2 \%$ of women were placed in different categories by the two versions of the eight-class schema.

(21) Using the data-set which contains the $P C S$ recoding of the 1977 survey has led to the inclusion for the same field of one more man $(9,408$ compared to 9,407$)$ and two more women $(4,558$ compared to 4,556$)$ than in the original data-set for this same survey, which are negligible differences. Tables III to VI show the total unweighted frequencies in lines and columns to give an approximate indication of the accuracy of the corresponding distributions of percentages. 
spectively $11 \%$ and $18 \%$ of sons in 1993 compared to $2 \%$ and $8 \%$ in 1953 , $5 \%$ and $20 \%$ of daughters in 1993 compared to $0 \%$ and $2 \%$ in 1953). It is also noteworthy that although women from all social classes have benefited from the considerable increase in the number of jobs for higher-grade professionals (the frequency of this social destination has increased in forty years whichever class origin) the same does not hold true for men: in the nineties as in the fifties slightly more than four out of ten sons of higher-grade professionals remained in the same category as their father and this stability contrasts with the increase which has occurred for other social classes, particularly among the sons of farmers and smallholders, artisans or shopkeepers, non-manual workers or manual workers (as we have seen already). Finally, the frequency with which men with different social origins belong to what Chenu (1990) describes as l'archipel des employés (i.e. the varied group of non-manual workers) has remained practically unchanged over forty years, while for women this frequency has increased, often considerably, among those with origins in most of the categories in our class schema.

Table V and Table VI look at the same mobility tables from the complementary viewpoint of the social recruitment of different occupational categories. Self-recruitment among male and female farmers and smallholders has remained very stable and at a very high level throughout the studied period, while among agricultural workers it has fallen and been replaced by increasingly frequent manual worker origins. Both male and female artisans and shopkeepers less frequently have origins among the self-employed petty bourgeoisie than in the past; on the other hand, more of them are the children of manual workers and their supervisors, but also of higher-grade or middlegrade professionals. Analogous trends, at least for men, can be observed in the change in the social recruitment of heads of undertakings, large shopkeepers and liberal professions. The increase in the number of higher-grade professions has led to a reduction, in the male population, in the proportion of those in this class who originate from it, but this trend has been reversed in the case of women. In both cases, however, recruitment of higher-grade professionals from the working class has become more frequent over our forty year period. The social composition of the class of middle-grade professionals and the class of non-manual workers has remained fairly constant for both men and women between the middle and the end of the century. Finally, self-recruitment among the working class began by falling, until the seventies, and then increased after that date. This irregular variation exactly matches the increase followed by the progressive decrease in the proportion of male and female manual workers who are the sons or daughters of a farmer or smallholder. 
1953 - French and foreign men in the workforce aged between 30 and 59 1970, 1977, 1985, 1993 - Working French men aged between 35 and 59

\begin{tabular}{|c|c|c|c|c|c|c|c|c|c|c|c|}
\hline Son & & 1 & 2 & 3 & 4 & 5 & 6 & 7 & 8 & Total & $(\mathrm{N})$ \\
\hline $\begin{array}{l}1 \text { Farmer or smallholder } \\
\text { (Farmer or smallholder) }\end{array}$ & $\begin{array}{c}1953 \\
1970 \\
1977 C S P \\
1977 P C S \\
1985 \\
1993\end{array}$ & $\begin{array}{lr}58 & \\
43 & \\
38 & \\
& 38 \\
& 34 \\
& 27 \\
& \end{array}$ & $\begin{array}{l}3 \\
3 \\
2 \\
2\end{array}$ & $\begin{array}{ll}8 & \\
6 & \\
6 & \\
& 8 \\
& 9 \\
& 9 \\
& 7\end{array}$ & $\begin{array}{l}1 \\
2 \\
1\end{array}$ & $\begin{array}{rr}1 & \\
2 & \\
3 & \\
& 3 \\
& 4 \\
& 10\end{array}$ & $\begin{array}{rr}3 & \\
4 & \\
5 & \\
& 6 \\
& 9 \\
& 10\end{array}$ & $\begin{array}{r}5 \\
9 \\
10\end{array}$ & $\begin{array}{ll}18 & \\
30 & \\
33 & \\
& 35 \\
& 34 \\
& 35\end{array}$ & $\begin{array}{l}100 \\
100 \\
100 \\
100 \\
100 \\
100\end{array}$ & $\begin{array}{ll}1 & 106 \\
1 & 973 \\
2 & 279 \\
2 & 298 \\
1 & 771 \\
& 772\end{array}$ \\
\hline $\begin{array}{l}2 \text { Farm worker } \\
\text { (Farm worker) }\end{array}$ & $\begin{array}{c}1953 \\
1970 \\
1977 C S P \\
1977 P C S \\
1985 \\
1993\end{array}$ & $\begin{array}{rr}12 & \\
9 & \\
4 & \\
& 4 \\
& 5 \\
& 3\end{array}$ & $\begin{array}{rr}29 & \\
16 & \\
12 & \\
& 12 \\
& 7 \\
& 5\end{array}$ & $\begin{array}{rr}11 & \\
8 & \\
7 & \\
& 7 \\
& 10 \\
& 10\end{array}$ & $\begin{array}{l}1 \\
1 \\
2\end{array}$ & $\begin{array}{ll}0 & \\
2 & \\
2 & \\
& 2 \\
& 3 \\
& \\
& 4\end{array}$ & $\begin{array}{rr}0 & \\
4 & \\
6 & \\
& 6 \\
& 11 \\
& 14\end{array}$ & $\begin{array}{rr}7 & \\
11 & \\
11 & \\
& 7 \\
& 10 \\
& 11\end{array}$ & $\begin{array}{ll}41 & \\
49 & \\
57 & \\
& 61 \\
& 53 \\
& 51\end{array}$ & $\begin{array}{l}100 \\
100 \\
100 \\
100 \\
100 \\
100\end{array}$ & $\begin{array}{l}327 \\
518 \\
402 \\
416 \\
339 \\
131\end{array}$ \\
\hline $\begin{array}{l}3 \text { Artisan, } \\
\text { small shopkeeper } \\
\text { (Artisan, } \\
\text { shopkeeper and } \\
\text { assimilated } \\
\text { occupations) }\end{array}$ & $\begin{array}{c}1953 \\
1970 \\
1977 \text { CSP } \\
1977 \text { PCS } \\
1985 \\
1993\end{array}$ & $\begin{array}{l}3 \\
2 \\
2\end{array}$ & $\begin{array}{l}1 \\
2 \\
1\end{array}$ & $\begin{array}{ll}47 & \\
26 & \\
22 & \\
& 27 \\
& 26 \\
& 27\end{array}$ & $\begin{array}{l}4 \\
7 \\
7\end{array}$ & $\begin{array}{rr}3 & \\
10 & \\
13 & \\
& 12 \\
& 16 \\
& 17\end{array}$ & $\begin{array}{rr}6 & \\
12 & \\
11 & \\
& 15 \\
& 17 \\
& 17\end{array}$ & $\begin{array}{l}10 \\
12 \\
14\end{array}$ & $\begin{array}{l}26 \\
29 \\
29 \\
30 \\
\\
31 \\
\\
26 \\
24\end{array}$ & $\begin{array}{l}100 \\
100 \\
100 \\
100 \\
100 \\
100\end{array}$ & $\begin{array}{r}545 \\
1346 \\
1192 \\
1496 \\
1255 \\
446\end{array}$ \\
\hline $\begin{array}{l}4 \text { Head of undertaking, } \\
\text { large shopkeeper, } \\
\text { liberal profession } \\
\text { (Head of undertaking } \\
\text { with } 10 \text { or more employees, } \\
\text { liberal profession) }\end{array}$ & $\begin{array}{c}1953 \\
1970 \\
1977 \text { CSP } \\
1977 \text { PCS } \\
1985 \\
1993\end{array}$ & $\begin{array}{l}2 \\
1 \\
1\end{array}$ & $\begin{array}{ll}1 & \\
1 & \\
0 & \\
& 0 \\
& 0 \\
& 0\end{array}$ & $\begin{array}{rr}12 & \\
11 & \\
14 & \\
& 7 \\
& 15 \\
& 9\end{array}$ & $\begin{array}{lr}45 & \\
24 & \\
20 & \\
& 31 \\
& 29 \\
& 23\end{array}$ & $\begin{array}{ll}13 & \\
24 & \\
30 & \\
& 31 \\
& 32 \\
& 35\end{array}$ & $\begin{array}{rr}6 & \\
13 & \\
12 & \\
& 14 \\
& 13 \\
& 18\end{array}$ & $\begin{array}{r}7 \\
13 \\
9\end{array}$ & $\begin{array}{rr}14 & \\
13 & \\
14 & \\
& 10 \\
& 8 \\
& 7\end{array}$ & $\begin{array}{l}100 \\
100 \\
100 \\
100 \\
100 \\
100\end{array}$ & $\begin{array}{r}85 \\
573 \\
503 \\
215 \\
285 \\
106\end{array}$ \\
\hline
\end{tabular}




\begin{tabular}{|c|c|c|c|c|c|c|c|c|c|c|c|}
\hline \multirow{6}{*}{$\begin{array}{l}5 \text { Higher-grade professional } \\
\text { (Professional, higher-grade } \\
\text { intellectual profession) }\end{array}$} & 1953 & 3 & 0 & 13 & 8 & 43 & 19 & 13 & 1 & 100 & 70 \\
\hline & 1970 & 2 & 0 & 3 & 9 & 45 & 19 & 12 & 10 & 100 & 634 \\
\hline & 1977 CSP & 2 & 0 & 4 & 8 & 45 & 23 & 9 & 9 & 100 & 537 \\
\hline & 1977 PCS & 2 & 0 & 5 & 9 & 45 & 24 & 5 & 10 & 100 & 511 \\
\hline & 1985 & 0 & 0 & 6 & 12 & 46 & 24 & 6 & 6 & 100 & 639 \\
\hline & 1993 & 0 & 0 & 8 & 13 & 41 & 21 & 8 & 9 & 100 & 272 \\
\hline \multirow{6}{*}{$\begin{array}{l}6 \text { Middle-grade professional } \\
\text { (Intermediate profession) }\end{array}$} & 1953 & 0 & 0 & 11 & 8 & 13 & 25 & 24 & 19 & 100 & 67 \\
\hline & 1970 & 0 & 0 & 5 & 5 & 27 & 32 & 14 & 17 & 100 & 519 \\
\hline & 1977 CSP & 0 & 0 & 4 & 6 & 30 & 31 & 12 & 17 & 100 & 496 \\
\hline & 1977 PCS & 1 & 0 & 6 & 4 & 27 & 31 & 10 & 21 & 100 & 535 \\
\hline & 1985 & 0 & 0 & 8 & 6 & 31 & 27 & 11 & 17 & 100 & 674 \\
\hline & 1993 & 1 & 0 & 6 & 8 & 31 & 31 & 9 & 14 & 100 & 299 \\
\hline 7 Non-manual worker, & 1953 & 6 & 0 & 9 & 3 & 11 & 15 & 21 & 35 & 100 & 257 \\
\hline service worker, & 1970 & 1 & 1 & 9 & 3 & 12 & 18 & 18 & 38 & 100 & 1241 \\
\hline other employee & 1977 CSP & 1 & 1 & 7 & 2 & 16 & 22 & 18 & 33 & 100 & 1029 \\
\hline (Non-manual worker) & 1977 PCS & 1 & 0 & 9 & 2 & 15 & 24 & 15 & 34 & 100 & 809 \\
\hline & 1985 & 1 & 0 & 9 & 2 & 20 & 24 & 17 & 27 & 100 & 809 \\
\hline & 1993 & 0 & 0 & 7 & 3 & 19 & 26 & 14 & 31 & 100 & 459 \\
\hline \multirow{6}{*}{$\begin{array}{l}8 \text { Supervisor of manual workers, } \\
\text { manual worker } \\
\text { (Supervisor of manual workers, } \\
\text { manual worker) }\end{array}$} & 1953 & 3 & 2 & 11 & 0 & 2 & 8 & 12 & 62 & 100 & 1026 \\
\hline & 1970 & 1 & 1 & 7 & 2 & 5 & 12 & 14 & 58 & 100 & 3207 \\
\hline & 1977 CSP & 1 & 1 & 7 & 2 & 7 & 13 & 14 & 55 & 100 & 2969 \\
\hline & 1977 PCS & 1 & 1 & 8 & 1 & 6 & 14 & 10 & 59 & 100 & 3128 \\
\hline & 1985 & 1 & 0 & 10 & 1 & 10 & 16 & 11 & 51 & 100 & 3055 \\
\hline & 1993 & 0 & 0 & 8 & 1 & 11 & 18 & 11 & 51 & 100 & 1528 \\
\hline \multirow[t]{6}{*}{ Total } & 1953 & 22 & 6 & 15 & 3 & 3 & 6 & 10 & 35 & 100 & 3483 \\
\hline & 1970 & 14 & 3 & 9 & 4 & 8 & 11 & 13 & 38 & 100 & 10011 \\
\hline & 1977 CSP & 11 & 2 & 9 & 4 & 11 & 12 & 13 & 38 & 100 & 9407 \\
\hline & 1977 PCS & 11 & 2 & 11 & 2 & 10 & 14 & 9 & 41 & 100 & 9408 \\
\hline & 1985 & 8 & 1 & 12 & 4 & 14 & 16 & 9 & 36 & 100 & 8827 \\
\hline & 1993 & 5 & 1 & 10 & 4 & 16 & 19 & 10 & 35 & 100 & 4013 \\
\hline
\end{tabular}

Interpretation: Of 100 sons of farmers or smallholders in employment in 1953,58 were farmers and smallholders. This was true for 27 in 1993. 
1953 - French and foreign women in the workforce aged between 30 and 59 1970, 1977, 1985, 1993 - Working French women aged between 35 and 59

\begin{tabular}{|c|c|c|c|c|c|c|c|c|c|c|c|}
\hline Daughter & & 1 & 2 & 3 & 4 & 5 & 6 & 7 & 8 & Total & $(\mathrm{N})$ \\
\hline $\begin{array}{l}1 \text { Farmer or smallholder } \\
\text { (Farmer or smallholder) }\end{array}$ & $\begin{array}{c}1953 \\
1970 \\
1977 \text { CSP } \\
1977 \text { PCS } \\
1985 \\
1993\end{array}$ & $\begin{array}{ll}65 & \\
52 & \\
43 & \\
& 43 \\
& 32 \\
& 21\end{array}$ & $\begin{array}{ll}2 & \\
1 & \\
1 & \\
& \\
& 1 \\
& 1 \\
& \\
& 0\end{array}$ & $\begin{array}{rr}12 & \\
10 & \\
8 & \\
& 8 \\
& 9 \\
& \\
& 8\end{array}$ & $\begin{array}{l}0 \\
0 \\
1\end{array}$ & $\begin{array}{l}0 \\
1 \\
1\end{array}$ & $\begin{array}{rr}2 & \\
4 & \\
6 & \\
& 6 \\
& 11 \\
& 17\end{array}$ & $\begin{array}{ll}10 & \\
15 & \\
22 & \\
& 28 \\
& 34 \\
& 40\end{array}$ & $\begin{array}{rr}9 & \\
17 & \\
18 & \\
& 13 \\
& 11 \\
& 11\end{array}$ & $\begin{array}{l}100 \\
100 \\
100 \\
100 \\
100 \\
100\end{array}$ & $\begin{array}{r}781 \\
865 \\
1065 \\
1072 \\
1042 \\
634\end{array}$ \\
\hline $\begin{array}{l}2 \text { Farm worker } \\
\text { (Farm worker) }\end{array}$ & $\begin{array}{c}1953 \\
1970 \\
1977 \text { CSP } \\
1977 \text { PCS } \\
1985 \\
1993\end{array}$ & $\begin{array}{rr}19 & \\
12 & \\
13 & \\
& 13 \\
& 8 \\
& 5\end{array}$ & $\begin{array}{r}13 \\
9 \\
1\end{array}$ & $\begin{array}{rr}20 & \\
11 & \\
11 & \\
& 11 \\
& 10 \\
& 7\end{array}$ & $\begin{array}{ll}0 & \\
0 & \\
0 & \\
& 0 \\
& 1 \\
& \\
& 1\end{array}$ & $\begin{array}{l}1 \\
1 \\
3\end{array}$ & $\begin{array}{rr}2 & \\
3 & \\
7 & \\
& 5 \\
& 7 \\
& 12\end{array}$ & $\begin{array}{ll}24 & \\
36 & \\
39 & \\
& 49 \\
& 56 \\
& 47\end{array}$ & $\begin{array}{ll}22 & \\
29 & \\
28 & \\
& 20 \\
& 17 \\
& 25\end{array}$ & $\begin{array}{l}100 \\
100 \\
100 \\
100 \\
100 \\
100\end{array}$ & $\begin{array}{l}160 \\
164 \\
211 \\
208 \\
217 \\
124\end{array}$ \\
\hline $\begin{array}{l}3 \text { Artisan, small shopkeeper } \\
\text { (Artisan, shopkeeper } \\
\text { and assimilated } \\
\text { occupations) }\end{array}$ & $\begin{array}{c}1953 \\
1970 \\
1977 \text { CsP } \\
1977 \text { PCS } \\
1985 \\
1993\end{array}$ & $\begin{array}{l}9 \\
7 \\
4\end{array}$ & $\begin{array}{l}0 \\
0 \\
0\end{array}$ & $\begin{array}{ll}48 & \\
30 & \\
24 & \\
& 24 \\
& 19 \\
& 11\end{array}$ & $\begin{array}{l}2 \\
2 \\
3\end{array}$ & $\begin{array}{rr}3 & \\
2 & \\
5 & \\
& 5 \\
& 8 \\
& \\
& 13\end{array}$ & $\begin{array}{rr}6 & \\
12 & \\
16 & \\
& 18 \\
& 27 \\
& 28\end{array}$ & $\begin{array}{ll}19 & \\
35 & \\
35 & \\
& 38 \\
& 35 \\
& 37\end{array}$ & $\begin{array}{rr}13 & \\
12 & \\
13 & \\
& 10 \\
& 6 \\
& 7\end{array}$ & $\begin{array}{l}100 \\
100 \\
100 \\
100 \\
100 \\
100\end{array}$ & $\begin{array}{l}278 \\
506 \\
578 \\
709 \\
676 \\
372\end{array}$ \\
\hline $\begin{array}{l}4 \text { Head of undertaking, } \\
\text { large shopkeeper, } \\
\text { liberal profession } \\
\text { (Head of undertaking } \\
\text { with } 10 \text { or more } \\
\text { employees, liberal profession) }\end{array}$ & $\begin{array}{c}1953 \\
1970 \\
1977 \text { CSP } \\
1977 \text { PCS } \\
1985 \\
1993\end{array}$ & $\begin{array}{l}6 \\
2 \\
2\end{array}$ & $\begin{array}{ll}0 & \\
0 & \\
0 & \\
& 0 \\
& 0 \\
& 0\end{array}$ & $\begin{array}{rr}12 & \\
26 & \\
16 & \\
& 8 \\
& \\
& \\
& 4 \\
4\end{array}$ & $\begin{array}{rr}40 & \\
7 & \\
7 & \\
& 13 \\
& 9 \\
& 17\end{array}$ & $\begin{array}{rr}6 & \\
12 & \\
13 & \\
& 16 \\
& 21 \\
24\end{array}$ & $\begin{array}{l}12 \\
26 \\
26 \\
\\
32 \\
28 \\
25\end{array}$ & $\begin{array}{l}21 \\
24 \\
30 \\
\\
\\
28 \\
24 \\
26\end{array}$ & $\begin{array}{l}3 \\
3 \\
6\end{array}$ & $\begin{array}{l}100 \\
100 \\
100 \\
100 \\
100 \\
100\end{array}$ & $\begin{array}{r}33 \\
179 \\
228 \\
103 \\
169 \\
79\end{array}$ \\
\hline
\end{tabular}


5 Higher-grade professional (Professional, higher-grade intellectual profession)

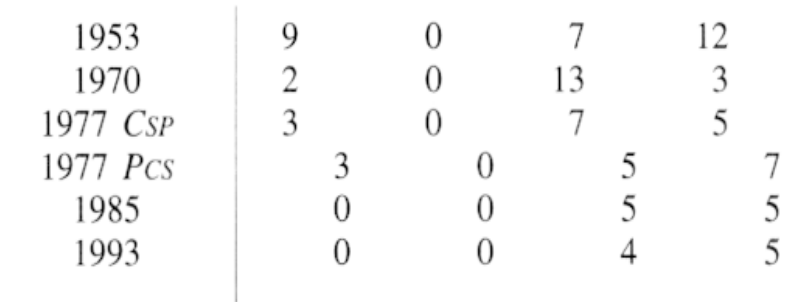

$\begin{array}{lll}\mathbf{1 4} & 25 & 21 \\ \mathbf{1 5} & 30 & 32\end{array}$

\begin{tabular}{l|ll}
12 & 100 & 43
\end{tabular}

24

$\begin{array}{ll}19 & 36\end{array}$

$\begin{array}{lll}19 & 36 & 28\end{array}$

28

$\begin{array}{lll}33 & 28 & 26\end{array}$

\begin{tabular}{l|l}
5 & 100
\end{tabular}

182

6 Middle-grade professional

(Intermediate profession)

7 Non-manual worker,

service worker,

other employee

(Non-manual worker

195

1970

1977 CSP

1977 PCS

1985

1993

1953

1970

1977 CSP

1977 PCS

1985

1993

8 Supervisor of manual workers,

manual worker

(Supervisor of manual workers,

manual worker)

\begin{tabular}{|c|c|c|c|}
\hline 0 & 13 & 3 & 8 \\
\hline 0 & 7 & 3 & 12 \\
\hline 0 & 13 & 5 & 9 \\
\hline 0 & 16 & 2 & 9 \\
\hline 0 & 6 & 3 & 13 \\
\hline 0 & 4 & 1 & 19 \\
\hline
\end{tabular}

$35 \quad 30$

32

$35 \quad 32$

$\begin{array}{ll}\mathbf{3 5} & 36 \\ \mathbf{3 7} & 33\end{array}$

5

$2 \quad 100$

219
405

\begin{tabular}{l|ll}
3 & 100 & 405 \\
4 & 100 & 245
\end{tabular}

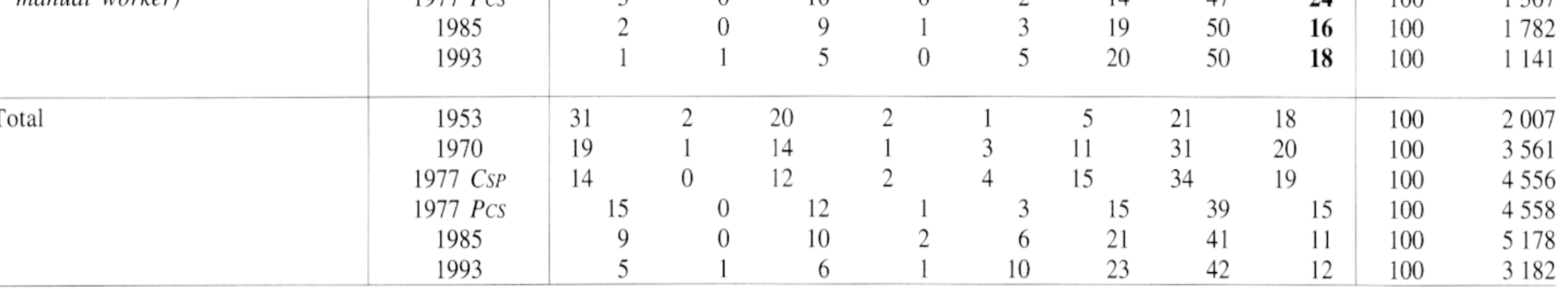

Interpretation: Of 100 daughters of farmers or smallholders in employment in 1953, 65 were farmers and smallholders. This was true for 21 in 1993.

$\frac{\sqrt{2}}{5}$




\section{Change between 1953 and 1993}

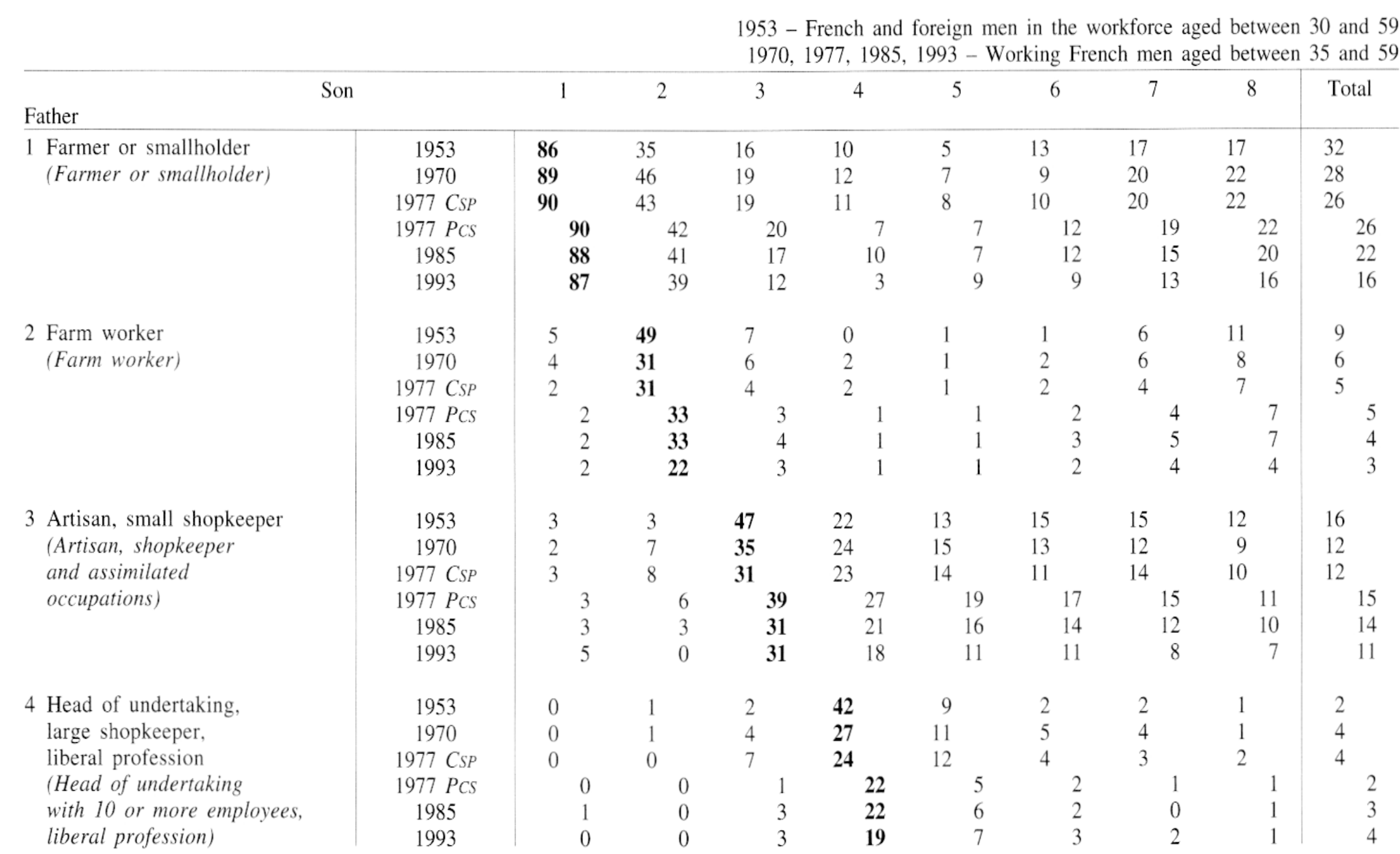


5 Higher-grade professional (Professional, higher-grade intellectual profession)

6 Middle-grade professional (Intermediate profession)

7 Non-manual worker, service worker, other employee (Non-manual worker)

8 Supervisor of manual workers,
manual worker
(Supervisor of manual workers,
manual worker)

(N)

Total (at each date)

\begin{tabular}{|c|c|c|c|c|}
\hline 1953 & 0 & 0 & 2 & 7 \\
\hline 1970 & 1 & 0 & 1 & 9 \\
\hline 1977 CSP & 1 & 0 & 2 & 10 \\
\hline 1977 PCS & 1 & 0 & 2 & 15 \\
\hline 1985 & 0 & 2 & 3 & 19 \\
\hline 1993 & 0 & 0 & 6 & 23 \\
\hline
\end{tabular}

25

18

\begin{tabular}{l|llll}
1953 & 0 & 0 & 1 & 5
\end{tabular}

1970

1977 CSP

1977 PCS

1985

1993

1953

1970

1977 CSP

1977 PCS

1985

1993

$\begin{array}{ll}0 & 0 \\ 0 & 0\end{array}$

0

1
2
2

$$
\begin{aligned}
& 5 \\
& 7
\end{aligned}
$$

$\begin{array}{lrr}3 & 8 & 12\end{array}$

$\begin{array}{lll}4 & 12 & 14 \\ 5 & 15 & 15\end{array}$

8

6

27

\begin{tabular}{rrrr|l}
8 & $\mathbf{8}$ & 5 & 1 & 2 \\
\hline & $\mathbf{1 1}$ & 4 & 2 & 4
\end{tabular}

11

11

11

11
13

6

$\begin{array}{rrrrrrrr}2 & & 0 & & 4 & 9 & \\ 1 & & 3 & & 10 & & 8 & \\ 1 & & 3 & & 9 & & 7 & \\ & 1 & & 1 & & 7 & & 7 \\ & 1 & & 4 & & 7 & & 4 \\ & 1 & & 7 & & 9 & & 7\end{array}$

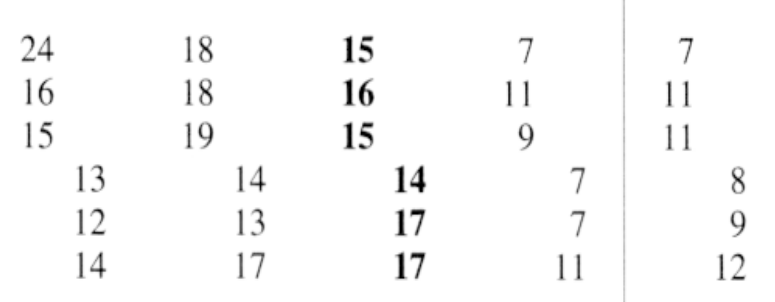

\begin{tabular}{|l|llllllll|l}
1953 & 4 & 12 & 21 & 5 & 15 & 37 & 37 & $\mathbf{5 1}$ & 30 \\
\hline
\end{tabular}

\begin{tabular}{l|lllrlllll|}
1953 & 4 & 12 & 21 & 5 & 15 & 37 & 37 & $\mathbf{5 1}$ & 30 \\
1970 & 3 & 12 & 23 & 13 & 18 & 35 & 35 & $\mathbf{4 6}$ & 31 \\
\hline
\end{tabular}

\begin{tabular}{l|lllll}
1977 CSP & 3 & 14 & 26 & 16 & 20
\end{tabular}

1977 PCS

1985

1993

$\begin{array}{ll}3 & 18 \\ 5 & 17\end{array}$

$\begin{array}{llll}5 & 17 & 25 & 13 \\ 4 & 28 & 31 & 11\end{array}$

20

34

37

47

33

\begin{tabular}{llll|l}
22 & 35 & 39 & $\mathbf{4 9}$ & 35 \\
25 & 36 & 40 & $\mathbf{5 1}$ & 36 \\
25 & 37 & 43 & $\mathbf{5 6}$ & 39 \\
\hline
\end{tabular}

\begin{tabular}{|c|c|c|c|c|c|c|c|c|}
\hline 4 & 28 & 31 & 14 & 25 & 37 & 43 & 56 & 39 \\
\hline 100 & 100 & 100 & 100 & 100 & 100 & 100 & 100 & 100 \\
\hline
\end{tabular}

100

100

\begin{tabular}{rr|r}
100 & 100 & 100 \\
\hline 342 & 1230 & 3483 \\
985 & 3683 & 10011 \\
1034 & 3244 & 9407 \\
703 & 3516 & 9408 \\
673 & 2697 & 8827 \\
391 & 1394 & 4013
\end{tabular}

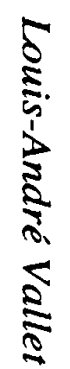

Interpretation: Of 100 farmers or smallholders in 1953, 86 were the sons of farmers and smallholders. This was true for 87 in 1993. 


\begin{tabular}{|c|c|c|c|c|c|c|c|c|c|c|}
\hline Daughter & & 1 & 2 & 3 & 4 & 5 & 6 & 7 & 8 & Total \\
\hline $\begin{array}{l}1 \text { Farmer or smallholder } \\
\text { (Farmer or smallholder) }\end{array}$ & $\begin{array}{c}1953 \\
1970 \\
1977 C S P \\
1977 P_{C S} \\
1985 \\
1993\end{array}$ & $\begin{array}{lr}83 & \\
84 & \\
81 & \\
& 82 \\
& 83 \\
& 74\end{array}$ & $\begin{array}{ll}28 & \\
30 & \\
62 & \\
& 70 \\
& 59 \\
& 25\end{array}$ & $\begin{array}{ll}23 & \\
22 & \\
19 & \\
& 19 \\
& 20 \\
& 22\end{array}$ & $\begin{array}{rr}3 & \\
6 & \\
11 & \\
& 7 \\
& 7 \\
& \\
& 0\end{array}$ & $\begin{array}{rr}14 & \\
13 & \\
9 & \\
& 7 \\
& 6 \\
& 4\end{array}$ & $\begin{array}{ll}18 & \\
11 & \\
11 & \\
& 12 \\
& 13 \\
& 13\end{array}$ & $\begin{array}{ll}18 & \\
15 & \\
18 & \\
& 20 \\
& 19 \\
& 17\end{array}$ & $\begin{array}{ll}18 & \\
25 & \\
26 & \\
& 23 \\
& 22 \\
& 16\end{array}$ & $\begin{array}{ll}39 & \\
30 & \\
27 & \\
& 27 \\
& 23 \\
& 17\end{array}$ \\
\hline $\begin{array}{l}2 \text { Farm worker } \\
\text { (Farm worker) }\end{array}$ & $\begin{array}{c}1953 \\
1970 \\
1977 \text { CSP } \\
1977 \text { PCS } \\
1985 \\
1993\end{array}$ & $\begin{array}{ll}5 & \\
4 & \\
5 & \\
& 5 \\
& 4 \\
& 4\end{array}$ & $\begin{array}{rr}48 & \\
54 & \\
8 & \\
& 12 \\
& 4 \\
& 0\end{array}$ & $\begin{array}{ll}8 & \\
4 & \\
5 & \\
& 5 \\
& 5 \\
& 4\end{array}$ & $\begin{array}{ll}0 & \\
2 & \\
0 & \\
& 0 \\
& 2 \\
& \\
& 3\end{array}$ & $\begin{array}{ll}0 & \\
1 & \\
1 & \\
& 1 \\
& 1 \\
& 1\end{array}$ & $\begin{array}{ll}3 & \\
1 & \\
2 & \\
& 2 \\
& 2 \\
& 2 \\
& 2\end{array}$ & $\begin{array}{ll}9 & \\
7 & \\
6 & \\
& 6 \\
& 6 \\
& 4\end{array}$ & $\begin{array}{rr}10 & \\
8 & \\
8 & \\
& 7 \\
& 7 \\
& 7\end{array}$ & $\begin{array}{ll}8 & \\
6 & \\
5 & \\
& 5 \\
& 4 \\
& 4\end{array}$ \\
\hline $\begin{array}{l}3 \text { Artisan, small shopkeeper } \\
\text { (Artisan, shopkeeper } \\
\text { and assimilated } \\
\text { occupations) }\end{array}$ & $\begin{array}{c}1953 \\
1970 \\
1977 \text { CSP } \\
1977 \text { PCS } \\
1985 \\
1993\end{array}$ & $\begin{array}{ll}4 & \\
5 & \\
4 & \\
& 4 \\
& 3 \\
& 7\end{array}$ & $\begin{array}{rr}0 & \\
6 & \\
8 & \\
& 4 \\
& 4 \\
& 4 \\
& 12\end{array}$ & $\begin{array}{lr}34 & \\
29 & \\
26 & \\
& 30 \\
& 23 \\
& 21\end{array}$ & $\begin{array}{ll}17 & \\
19 & \\
19 & \\
& 18 \\
& 26 \\
& 10\end{array}$ & $\begin{array}{ll}32 & \\
11 & \\
15 & \\
& 20 \\
& 16 \\
& 15\end{array}$ & $\begin{array}{ll}16 & \\
16 & \\
13 & \\
& 19 \\
& 16 \\
& 15\end{array}$ & $\begin{array}{lr}12 & \\
15 & \\
13 & \\
& 15 \\
& 11 \\
& 10\end{array}$ & $\begin{array}{rr}10 & \\
8 & \\
9 & \\
& 10 \\
& 7 \\
& 7\end{array}$ & $\begin{array}{lr}14 & \\
14 & \\
13 & \\
& 15 \\
& 12 \\
& 12\end{array}$ \\
\hline $\begin{array}{l}4 \text { Head of undertaking, } \\
\text { large shopkeeper, } \\
\text { liberal profession } \\
\text { (Head of undertaking } \\
\text { with } 10 \text { or more } \\
\text { employees, liberal profession) }\end{array}$ & $\begin{array}{c}1953 \\
1970 \\
1977 \text { CSP } \\
1977 \text { PCS } \\
1985 \\
1993\end{array}$ & $\begin{array}{ll}0 & \\
0 & \\
1 & \\
& 0 \\
& 1 \\
& 1\end{array}$ & $\begin{array}{ll}0 & \\
0 & \\
0 & \\
& 0 \\
& 0 \\
& 0 \\
& 0\end{array}$ & $\begin{array}{ll}1 & \\
6 & \\
6 & \\
& 1 \\
& 3 \\
& 2\end{array}$ & $\begin{array}{lr}37 & \\
22 & \\
15 & \\
& \\
21 \\
14 \\
\\
37\end{array}$ & $\begin{array}{rr}9 & \\
14 & \\
11 & \\
& 7 \\
& 9 \\
& 6\end{array}$ & $\begin{array}{ll}4 & \\
8 & \\
7 & \\
& 3 \\
& 4 \\
& 3\end{array}$ & $\begin{array}{ll}2 & \\
2 & \\
3 & \\
& 1 \\
& 1 \\
& 2\end{array}$ & $\begin{array}{ll}0 & \\
1 & \\
1 & \\
& 0 \\
& 1 \\
& 0\end{array}$ & $\begin{array}{ll}2 & \\
3 & \\
4 & \\
& 2 \\
& \\
& 3 \\
& 3\end{array}$ \\
\hline
\end{tabular}




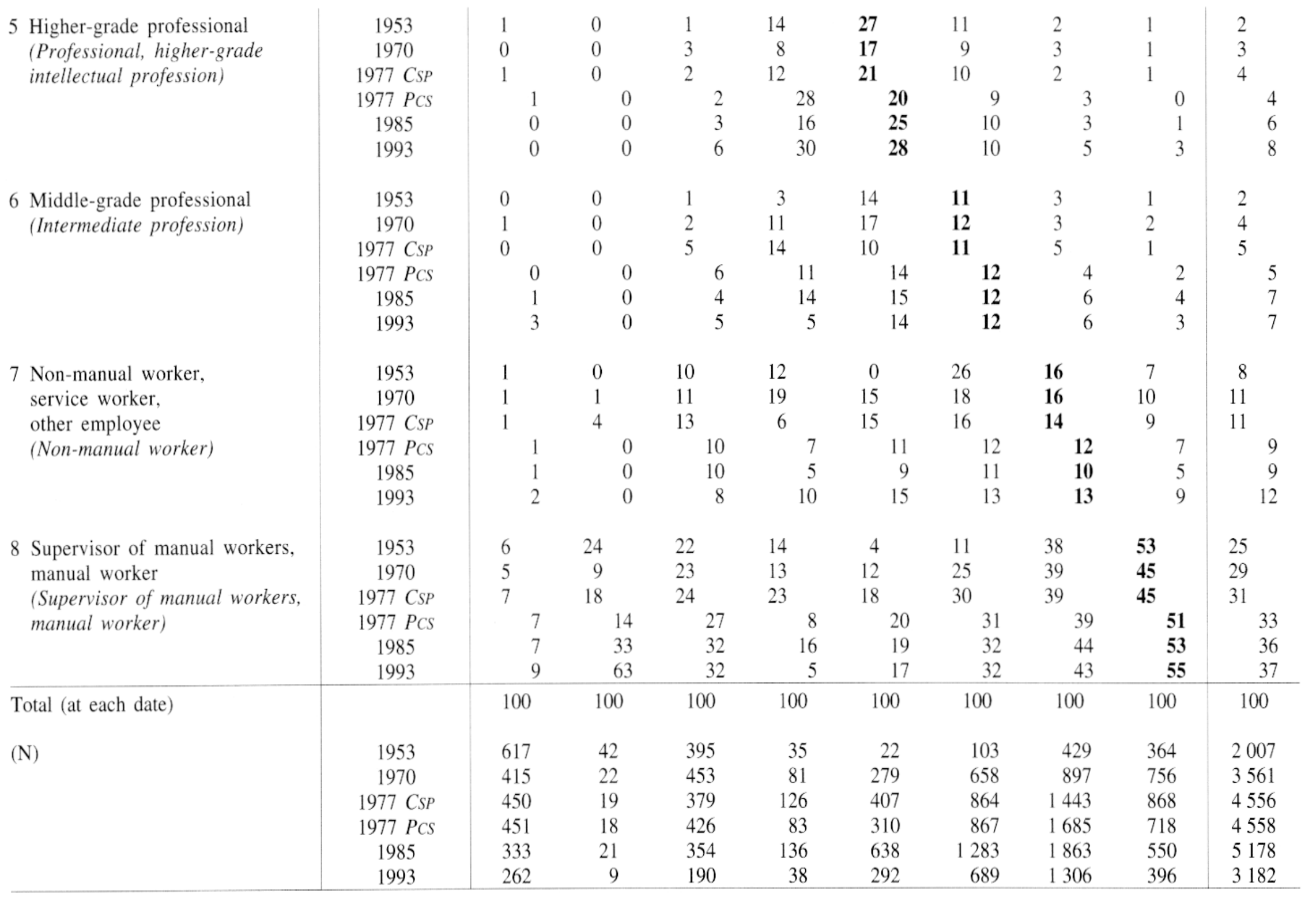

Interpretation: Of 100 women farmers or smallholders in 1953, 83 were the daughters of farmers and smallholders. This was true for 74 in 1993. 
In French society many changes have taken place in absolute intergenerational mobility rates over forty years. In particular, observed mobility has greatly increased. The fact that the proportion of individuals who remain in the same social class throughout their lives has declined might thus give members of the society the impression that class barriers and the inequality of opportunity have declined somewhat. In order to find out whether this has in fact occurred we need however to analyze social fluidity or the mobility regime.

\section{There was a slight, but continuous, increase in social fluidity between 1953 and 1993}

Let $t$ and $t$ ' be two dates, $i$ and $i$ ' two different social origins, $j$ and $j$ ' two different social destinations and od the odds ratio which measures, at date $t$, the intrinsic strength of the statistical association between these origins and these destinations:

$$
o d=\frac{m_{i j r} m_{i^{\prime} j^{\prime} t}}{m_{i j, t} m_{i{ }^{\prime} j t}}
$$

or alternatively $\log (o d)=\log \left(m_{i j t}\right)+\log \left(m_{i^{\prime} j^{\prime} t}\right)-\log \left(m_{i j^{\prime} t}\right)-\log \left(m_{i^{\prime} j t}\right)$

The hypothesis of constant social fluidity between date $t$ and date $t$ ' can be expressed by the log-linear model which postulates an absence of interaction between origin $(O)$, destination $(D)$ and time $(T)$, that is to say:

$$
\log \left(m_{i j t}\right)=\lambda+\lambda_{i}^{O}+\lambda_{j}^{D}+\lambda_{t}^{T}+\lambda_{i t}^{O T}+\lambda_{j t}^{D T}+\lambda_{i j}^{O D}
$$

From this model we can deduce that:

$$
\log (o d)=\left(\lambda_{i j}^{O D}+\lambda_{i^{\prime} j^{\prime}}^{O D}-\lambda_{i j^{\prime}}^{O D}-\lambda_{i^{\prime}{ }^{\prime}{ }^{\prime}}^{O D}\right)
$$

i.e. the logarithm of each odds ratio is expressed by means of parameters whose index does not include $t$. This means that the statistical association between social origin and destination does not vary over time. (22)

Let us now consider the following, more complex, model, which is in fact the log-multiplicative model of uniform difference (UNIDIFF) proposed by Erikson and Goldthorpe (1992) or Xie (1992):

$$
\log \left(m_{i j t}\right)=\lambda+\lambda_{i}^{O}+\lambda_{j}^{D}+\lambda_{t}^{T}+\lambda_{i t}^{o T}+\lambda_{j t}^{D T}+\beta_{i} \psi_{i j}
$$

(22) The presence in the model of $\lambda$ parameters -other than those $\left(\lambda_{i j}\right)$ which relate to the association between origin and destinationensures that the mobility tables estimated for dates $t$ and $t^{\prime}$ will have the same margins as the corresponding observed tables. This type of model therefore really does analyze the statistical association between social origin and position, once allowances have been made for changes in socio-occupational distributions. 
From this model we can deduce that:

$$
\log (o d)=\beta_{i}\left(\psi_{i j}+\psi_{i j^{\prime}}-\psi_{i j^{\prime}}-\psi_{i^{\prime} j}\right)
$$

i.e. the logarithm of each odds ratio is expressed as the product of two sets: the expression formed with the $\psi$ parameters captures the general, non time-dependent, form of the statistical association between the origins $i$ and $i$ ' and the destinations $j$ and $j$ ' which are considered; the parameter $\beta_{t}$, which is specific to the date in question, expresses the relative strength of the association between social origin and social destination at this instant.

A quality of the UNIDIFF model is therefore that it expresses the temporal variation in social fluidity in a highly parsimonious way: it takes the form of a straightforward comparison between two values, $\beta_{t}$ and $\beta_{t}$, which are characteristic of the dates $t$ and $t^{\prime}$. It is also easy to verify that the constant social fluidity model is just a specific type of UNIDIFF model which is obtained if we assume that the parameters $\beta_{t}$ and $\beta_{t}$. are strictly equal (in which case they are given the conventional value of 1 ).

Let us now assume that, in the estimation of the UNIDIFF model for mobility tables obtained at dates $t$ and $t$, the value of the parameter $\beta_{t}$ for the first date has been given the conventional value of $1 .{ }^{(23)}$ Estimating the parameter $\beta_{t}$, for the second date will therefore give the direction of the change in social fluidity between $t$ and $t$ '. More precisely, if $\beta_{t}$. is less than 1 , the logarithms of the odds ratios (which at date $t$ were either positive or negative depending on the case) will be uniformly nearer 0 at the date $t^{\prime}$. In other terms, an estimated value of $\beta_{t}$, which is less than 1 will correspond to the odds ratios being uniformly closer to 1 , that is to say that the association between social origin and destination is less strict at $t^{\prime}$ than it was at $t$ or, put another way, that social fluidity has increased. Conversely, an estimated value of $\beta_{t}$, which is greater than 1 means that there has been an increase in the strength of the association between class of origin and class of destination, that is to say a reduction in the general level of social fluidity, or an increase in inequality of opportunity during the period. (24)

Initially, we can apply this statistical estimation technique to the male mobility tables obtained in 1953 and 1970 . If no trend affects social mobility in French society between the two dates there is one chance in two that the esti-

(23) Which is what applies in the case of the estimation algorithm we use.

(24) Still assuming that $\beta_{r}$ is fixed at 1 , we have verified empirically that $\beta_{t^{\prime}}$ was equal to 0 in the (theoretical) situation where at the second date there was absolutely no association in the society between social origin and destination, i.e. that mobility or fluidity were perfect. If we let $\log (o d)^{\prime}$ be the logarithm of an odds ratio which is homologous to od but which refers to the date $t^{\prime}$, we obtain the following:

$$
\begin{gathered}
{\left[\log (o d)^{\prime}-\log (o d)\right] / \log (o d)=} \\
\left(\beta_{t}-\beta_{t}\right) / \beta_{t}=\beta_{t}-\beta_{t}
\end{gathered}
$$

$\beta_{t}-\beta$, can therefore be interpreted as the rate of variation in the statistical association between origin and destination from $t$ to $t^{\prime}$. For example, if $\beta_{r}$. is equal to 0.8 in the case where $\beta_{r}$ is equal to 1 , we would say that the general level of social fluidity had increased by $20 \%$ over the period. 
mated parameter $\beta_{1970}$ will be (slightly) less than 1 and also one chance in two that it will be (slightly) greater than 1 as the data, obtained from sample surveys, are by their very nature affected by random error. The same exercise can be repeated with the male tables for 1970 and 1977 (in the CSP version of our class schema), with those for 1977 and 1985 (this time using the PCS version of the 1977 data in order for the comparison to be as equitable as possible), and lastly with those for 1985 and 1993. The same process is also possible for female mobility tables.

We thus have eight tests in order to answer the same question. If there is no long-term trend towards increasing social fluidity in French society, the probability that all the estimated $\beta$ parameters will be less than 1 is very small:

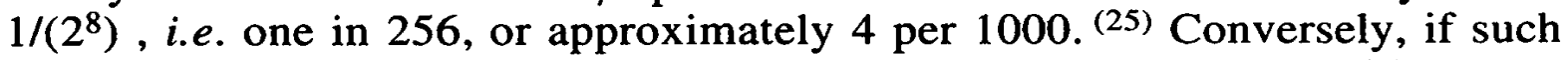
were to be the estimated values of the $\beta$ parameters, this would provide strong empirical support for the view that there has been a steady fall in the inequality of social opportunity in French society. Table VII shows the estimates we have made: the principal finding is that they conform point for point to the general pattern we have just described.

The log-multiplicative parameter which was fixed at 1 in 1953 was estimated at 0.888 for men in 1970 , and this difference is significant at the one per thousand level; (26) the same, however, does not apply for the variation which operates in the same direction and is apparent in the corresponding tables for women. Between 1970 and 1977 a trend towards increasing social fluidity reappears for both men and women; in this case it is significant for the latter and just fails to be significant for the former at the ten percent level. As far as the periods $1977-85$ and 1985-93 are concerned, the same general picture emerges: a trend for inequality of social opportunity to fall continues and is significantly apparent during one period for men and during another for women.

The same analysis can also be performed over longer periods by using both versions -firstly $C S P$, then $P C S$ - of our class schema. If we fix $\beta$ at 1 in 1953, its value becomes 0.900 in 1970 , then 0.861 in 1977 for men (for women the figures are respectively 0.957 and 0.843 ). For both sexes the improvement in fit which results from application of the UNIDIFF model instead of the constant social fluidity model is, in addition, significant at the level of one per thousand. In a quarter of a century, social fluidity has therefore increased by about $15 \%$ in French society. Over the period 1977-93 in the PCS version of our class schema change in the same direction was still present; if $\beta$ is fixed at 1 in 1977 , in the case of men it takes on a value of 0.945 in 1985 and 0.890 in 1993, and for women the corresponding values are 0.965 and 0.870 . Finally, in comparison with the constant social fluidity model, the improvement in fit caused by the UNIDIFF model which takes account of this trend is significant

(25) Although the tests are not, strictly speaking, independent as the same dates are used for men and women.

(26) The software we have used does not compute the standard error for the parameters of a log-multiplicative model. For the statistical tests we have therefore used the difference in likelihood ratio chi-square between the two nested models, i.e. the constant social fluidity and uniform difference models. 
TABLE VII. - Estimation of the UNIDIFF model for pairs of successive mobility tables

\begin{tabular}{|c|c|c|c|c|c|}
\hline \multirow[t]{2}{*}{ Model } & $\begin{array}{l}\text { Degrees } \\
\text { of } \\
\text { freedom }\end{array}$ & Chi-square & \multirow[t]{2}{*}{ Test } & \multicolumn{2}{|c|}{ Log-multiplicative parameters } \\
\hline & & & & & \\
\hline $\begin{array}{c}1953-1970 \\
\text { A }- \text { Constant social fluidity } \\
\text { B - Uniform difference } \\
\text { Difference (A) - (B) }\end{array}$ & $\begin{array}{l}47 \\
46\end{array}$ & $\begin{array}{c}108.653 \\
93.306 \\
15.347\end{array}$ & $\begin{array}{l}\mathrm{p}<.001 \\
\mathrm{p}<.001 \\
\quad \mathrm{p}<.001\end{array}$ & $\beta_{1953}=1.000$ & $\beta_{1970}=0.888$ \\
\hline $\begin{array}{c}1970-1977 \\
\text { A }- \text { Constant social fluidity } \\
\text { B - Uniform difference } \\
\text { Difference }(\mathrm{A})-(\mathrm{B})\end{array}$ & $\begin{array}{l}49 \\
48\end{array}$ & $\begin{array}{r}47.231 \\
44.620 \\
2.611\end{array}$ & $\begin{array}{l}\mathrm{ns} \\
\mathrm{ns}\end{array}$ & $\beta_{1970}=1.000$ & $\beta_{1977}=0.960$ \\
\hline $\begin{array}{c}1977-1985 \\
\text { A }- \text { Constant social fluidity } \\
\text { B - Uniform difference } \\
\text { Difference (A) - (B) }\end{array}$ & $\begin{array}{l}47 \\
46\end{array}$ & $\begin{array}{l}52.163 \\
47.452 \\
4.711\end{array}$ & $\begin{array}{l}\mathrm{ns} \\
\mathrm{ns} \\
\mathrm{p}<.05\end{array}$ & $\beta_{1977}=1.000$ & $\beta_{l 985}=0.944$ \\
\hline $\begin{array}{c}1985-1993 \\
\text { A }- \text { Constant social fluidity } \\
\text { B - Uniform difference } \\
\text { Difference (A) - (B) }\end{array}$ & $\begin{array}{l}48 \\
47\end{array}$ & $\begin{array}{r}71.961 \\
69.504 \\
2.457 \\
\end{array}$ & $\begin{array}{l}\mathrm{p}<.02 \\
\mathrm{p}<.02 \\
\quad \mathrm{~ns}\end{array}$ & $\beta_{1985}=1.000$ & $\beta_{1993}=0.944$ \\
\hline
\end{tabular}

Women

$$
1953-1970
$$

A - Constant social fluidity 46

B - Uniform difference 45

Difference (A) - (B)

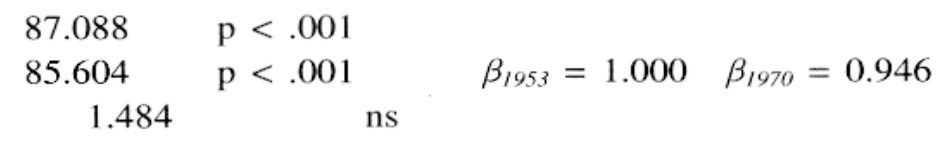
$1970-1977$

A - Constant social fluidity 46

B - Uniform difference 45

Difference (A) - (B) 1977 - 1985

A - Constant social fluidity 45

$\begin{array}{ccc}45 & 58.690 & \mathrm{p}<.10 \\ 44 & 58.086 & \mathrm{p}<.10 \\ & 1 & 0.604\end{array}$
$73.619 \quad \mathrm{p}<.01$
$64.834 \quad \mathrm{p}<.05$
8.785
$\mathrm{p}<.01$

$\beta_{1970}=1.000 \quad \beta_{1977}=0.884$

B - Uniform difference

Difference (A) - (B)

0.604

ns

$\beta_{1977}=1.000 \quad \beta_{1985}=0.968$

$$
1985-1993
$$

A - Constant social fluidity 45

B - Uniform difference 44

$61.441 \quad \mathrm{p}<.10$

$57.430 \quad \mathrm{p}<.10$

Difference (A) - (B)

44

4.011

$\mathrm{p}<.05$

French and foreign men aged between 30 and 59, currently or formerly in the labour force (PCS one-digit schema) 1977 - 1985 - 1993
A - Constant social fluidity 50
B - Uniform difference
50
48
83.648
$\mathrm{p}<.01$
$62.507 \quad \mathrm{p}<.10$
$\beta_{l 977}=1.000 \quad \beta_{l 985}=0.942$
Difference (A) - (B)
$2 \quad 21.141$
$\mathrm{p}<.001$
$\beta_{1993}=0.868$

Note: The number of degrees of freedom for each model can be adjusted in order to take account of zeros in the observed margin (OD) (Bishop, Fienberg and Holland, 1975, pp. 115-119). 
at the one percent level for men and the five percent level for women. Once more, therefore, over a sixteen year period, the general level of social fluidity has increased -or the inequality of opportunity has fallen- by about $12 \%$. (27)

The conclusion which emerges from the foregoing analyses is in clear contrast with that reached by recent French research. Far from having remained unchanged from the end of the 1970s to the beginning of the current decade, the strength of the association between individuals' classes of origin and the social positions they hold as a result of their occupation seems to have undergone a slow erosion, and this change furthermore closely follows a trend which had existed already within French society from the middle of the century. A plausible explanation for these differing conclusions could be that the UNIDIFF model is a powerful instrument for detecting even very slight variations in the mobility regime that previous research, based essentially on the temporal invariance model or an equivalent, was practically unable to reveal. Before accepting this explanation, we must, however, recognize that our study contrasts with previous research in one important respect, that of the class schema. In their work, Forsé (1997), Goux and Maurin (1997a, 1997b) and Merllié and Prévot (1997) all use the one-digit PCS code. However, we cannot a priori exclude the possibility that this code is more suitable for the recent period than our eight-fold class schema, as the latter is to a large extent derived from the desire to include old data from 1953 in the analysis. If this were to be the case and if we could not reproduce our results using the recent class schema the difference would no longer exist and our conclusion would be invalidated as it would originate from the use of a schema which could be said to draw distinctions between positions in society which are to a large degree outmoded today.

To explore this aspect, the last section of Table VII shows the results obtained for the 1977,1985 and 1993 mobility tables constructed using the one-digit PCS schema. The population considered corresponds to that covered in the research by $D$. Goux and É. Maurin, namely French and foreign men between the ages of 30 and 59 currently or formerly in the labour force. Of the three studies we have mentioned, it is this which has the broadest population. In comparison to our earlier analyses, foreigners have been added, as too have those in early retirement and the unemployed who have already worked at some time; the only group missing is the unemployed who have never

(27) It should be borne in mind that for 1970 to 1993 the data relate to French men and women between the ages of 35 and 59 with jobs. However, we cannot a priori exclude the possibility that the reduction in the legal retirement age and the increase towards the end of the period in the number of forms of early retirement have led in 1985 and 1993 to the selection among the older persons of a sample which is not very comparable with that obtained in 1977, and this could bias our results. We have checked this point by repeating our analyses for the period 1977-93 in two different ways, i.e. by reducing the scope (to working men and women between the ages of 35 and 54) and increasing the scope (to men and women between the ages of 35 and 59 currently or formerly in the workforce). We shall not, for the sake of brevity, give a detailed account of the results here. They differ very little from those given above and do not provide any grounds for changing our conclusion either way. The detailed results can be obtained from the author. 
worked, who were negligible in number in 1985 or 1993 in the age bracket in question. On the basis of these data the model of constant social fluidity is not acceptable at the one percent level, but the UNIDIFF model cannot be rejected at the five percent level, and in addition the improvement in fit which it provides is highly significant. Lastly, the log-multiplicative parameters reproduce, and even slightly amplify, the trend we have revealed: if we fix $\beta$ at 1 for 1977 it takes on a value of 0.942 in 1985 and 0.868 in 1993. It therefore does not seem possible to accept the authors' conclusion that "social inequalities seem neither stronger nor weaker today than one or two decades ago" (1997a, p. 25) and careful examination of the data and the estimations from the models provides illuminating clues as regards the changes which have occurred. According to the 1977 survey, in the studied population the chances of belonging to the class of professionals and higher-grade intellectual professions rather than the class of manual workers were 100 times greater for the sons from the first class than from the second; the same odds ratio has a value of 76 for the 1985 data and 39 for the 1993 data. The constant social fluidity model estimates this odds ratio at 72 at each date, but the UNIDIFF model reproduces the trend in the survey data quite faithfully, giving estimations of 92 in 1977,71 in 1985 and 51 in 1993. (28)

Thus, all our analyses agree that there has been a slight, but continuous, increase in social fluidity for both men and women over four decades. It is therefore natural to attempt to cover the whole of the studied period at once. Of course, the cost of such an undertaking is that analysis is based on three mobility tables (for 1953, 1970 and 1977) which use the old version of our class schema and two mobility tables (for 1985 and 1993) which use the more recent version. We can, however, hope that despite this heterogeneity the trend which we have observed will reappear, and this will amount to a test for the robustness of our result. It is moreover this global analysis which will allow us to examine the manner in which it is possible to reconcile this increase in the general level of social fluidity with the previous result that during the period 1953-77 there was a reduction in the chances of intergenerational immobility (Goldthorpe and Portocarero, 1981; Thélot, 1982; Vallet, 1991, 1992).

(28) Goux and Maurin analyzed tables with three or more dimensions, in particular the table which cross-classifies origin, educational attainment and social destination. Their modelling therefore dealt with the association between social origin and destination at a given level of educational attainment. As they did not analyze the two-dimensional origin-destination table which is the only one describing the total association between these two variables, they do not notice this important sign of increased openness in the intergenerational mobility regime in French society. 
Revue française de sociologie

\section{Modelling}

Let us return to our previous notation, where $t$ denotes one of the five survey dates, $i$ and $i$ ' are any two social origins (out of 8), $j$ and $j$ ' are any two social destinations (out of 8 ) and od is the odds ratio which measures the strength of the association between these origins and destinations at date $t$ :

$$
o d=\frac{m_{i j t} m_{i^{\prime} j^{\prime} t}}{m_{i j^{\prime} t} m_{i^{\prime} j t}}
$$

or alternatively $\log (o d)=\log \left(m_{i j t}\right)+\log \left(m_{i^{\prime} j^{\prime} t}\right)-\log \left(m_{i j^{\prime} t}\right)-\log \left(m_{i^{\prime} j t}\right)$

We can start to analyze the contingency table which cross-classifies origin (O), destination (D) and time (T) by means of the following log-linear model:

$$
\log \left(m_{i j t}\right)=\lambda+\lambda_{i}^{o}+\lambda_{j}^{D}+\lambda_{t}^{T}+\lambda_{i t}^{o T}+\lambda_{j t}^{D T}
$$

from which we can easily deduce that: $\log (o d)=0$ or alternatively $o d=1$. Such a model thus postulates that social origin and destination are independent for the survey year in question and expresses the hypothesis of perfect fluidity at each date. Although this is highly improbable, it provides us with a useful basis for assessing the extent to which more complex, and more realistic, models fit the data more closely. If we add the parameters $\lambda_{i j}$ which relate to the association between origin and destination, we obtain the constant social fluidity model:

$$
\log \left(m_{i j t}\right)=\lambda+\lambda_{i}^{o}+\lambda_{j}^{D}+\lambda_{t}^{T}+\lambda_{i t}^{o r}+\lambda_{j t}^{D r}+\lambda_{i j}^{o D}
$$

which implies that:

$$
\log (o d)=\left(\lambda_{i j}^{O D}+\lambda_{i^{\prime} j^{\prime}}^{O D}-\lambda_{i j^{\prime}}^{O D}-\lambda_{i^{\prime} j}^{O D}\right)
$$

We are now ready to consider two general approaches to analysis of temporal change in social fluidity. The first consists of assuming, on the basis of the research on France for the period 1953 to 1977 which we have just described, that social fluidity has remained constant apart from a variation over time in the chances of intergenerational immobility. An initial hypothesis -explored by Erikson and Goldthorpe (1992)- postulates that this variation has been the same for the different classes, but specific to each of the considered dates:

$$
\log \left(m_{i j t}\right)=\lambda+\lambda_{i}^{o}+\lambda_{j}^{D}+\lambda_{t}^{T}+\lambda_{i t}^{O T}+\lambda_{j t}^{D T}+\lambda_{i j}^{O D}+a_{t} d_{i j}
$$


where $d_{i j}=1$ if $i=j$ and $d_{i j}=0$ if not, and $\alpha_{1953}=0$ by convention (variations in the chances of social immobility will therefore be expressed by comparison with the first survey). A model of this type in fact implies that:

$\log (o d)=\left(\lambda_{i j}^{O D}+\lambda_{i^{\prime} j^{\prime}}^{O D}-\lambda_{i j^{\prime}}^{O D}-\lambda_{i^{\prime} j}^{O D}\right)$ if no diagonal cell is involved,

while, if $i=j$ and $i '=j '$ :

$\log (o d)=\left(\lambda_{i j}^{O D}+\lambda_{i^{\prime} j^{\prime}}^{O D}-\lambda_{i j^{\prime}}^{O D}-\lambda_{i^{\prime}{ }^{\prime} j}^{O D}\right)$ in 1953,

$\log (o d)=\left(\lambda_{i j}^{O D}+\lambda_{i^{\prime} j^{\prime}}^{O D}-\lambda_{i j^{\prime}}^{O D}-\lambda_{i^{\prime} j}^{O D}\right)+2 \alpha_{1970}$ in 1970 , etc.

It is still possible to formulate a more restrictive hypothesis than the one above. This leads to a very parsimonious model which only differs from the temporal invariance model in that it estimates an additional parameter. This hypothesis is that the temporal variation in the chances of immobility has followed a linear trend:

$$
\log \left(m_{i j t}\right)=\lambda+\lambda_{i}^{O}+\lambda_{j}^{D}+\lambda_{t}^{T}+\lambda_{i t}^{O T}+\lambda_{j t}^{D T}+\lambda_{i j}^{O D}+a_{l i n} d_{i j t}
$$

where $d_{i j t}=0$ if $i$ differs from $j$ while, if $i=j, d_{i j t}=0$ in 1953, 17 in 1970, 24 in 1977,32 in 1985 and 40 in 1993. The difference in likelihood ratio chi-square between models 2 and 4, which we shall from now on denote by (2)-(4), will provide a means of testing the significance of a linear temporal trend in the variation in the chances of immobility which is common to all classes. In the same way (4)-(3) will test the hypothesis that this linear trend accurately describes the changes in the chances of immobility which occur between the different surveys.

It now becomes possible to progressively loosen the quite strong constraints which apply to model 4 , first of all by allowing the chances of immobility to vary over time according to a linear trend which is not the same for different classes:

$$
\log \left(m_{i j t}\right)=\lambda+\lambda_{i}^{O}+\lambda_{j}^{D}+\lambda_{t}^{T}+\lambda_{i t}^{o T}+\lambda_{j t}^{D T}+\lambda_{i j}^{O D}+a_{i \text { lin }} d_{i j t}
$$

where $d_{i j t}$ is defined as above; (4)-(5) will therefore test whether the linear trend which affects the chances of immobility has been different for different classes. Finally, we can assume that the chances of immobility have been specific to each class at each date:

$$
\log \left(m_{i j t}\right)=\lambda+\lambda_{i}^{o}+\lambda_{j}^{D}+\lambda_{i}^{T}+\lambda_{i t}^{o r}+\lambda_{j t}^{D T}+\lambda_{i j}^{O D}+a_{i t} d_{i j}
$$

where $d_{i j}$ is defined as above and the role of the parameters $\alpha_{i t}$ is to achieve perfect fit of the diagonal of each mobility table; (5)-(6) will therefore test whether the temporal variations in the chances of immobility for different classes can really be expressed by means of linear trends.

We now have a structured viewpoint from which to consider temporal changes in the chances of immobility between different surveys. The loglinear models 3 to 6 all share the following feature: only those odds ratios 
which involve at least one diagonal cell change over time. In contrast, the second analysis approach - that which assumes there has been a trend in the general level of social fluidity-implies that each odds ratio has a specific value which varies between one survey and another. Here, we need to use more complex, log-multiplicative, models. This hypothesis can then take two forms, the first of which (the UNIDIFF model) we have already used in the previous section:

$$
\log \left(m_{i j t}\right)=\lambda+\lambda_{i}^{o}+\lambda_{j}^{D}+\lambda_{t}^{T}+\lambda_{i r}^{o T}+\lambda_{j r}^{D T}+\beta_{t} \psi_{i j}
$$

(Model 7)

which implies that:

$$
\log (\text { od })=\beta_{t}\left(\psi_{i j}+\psi_{i{ }^{\prime} j^{\prime}}-\psi_{i j^{\prime}}-\psi_{i^{\prime} j^{\prime}}\right)
$$

where $\beta_{1953}=1$. The second form is derived from the above results which seem to reveal a regular monotonic trend for the $\beta$ parameters. It postulates that these have varied according to a linear trend:

$$
\log \left(m_{i j t}\right)=\lambda+\lambda_{i}^{o}+\lambda_{j}^{D}+\lambda_{t}^{T}+\lambda_{i t}^{o T}+\lambda_{j t}^{D T}+\left(1+\beta_{\text {lin }} \text { year }\right) \psi_{i j}
$$

which implies that:

$$
\log (o d)=\left(1+\beta_{l i n} \text { year }\right)\left(\psi_{i j}+\psi_{i^{\prime} j^{\prime}}-\psi_{i j^{\prime}}-\psi_{i^{\prime} j}\right)
$$

where year is a quantitative variable equal to 0 in 1953,17 in 1970,24 in 1977,32 in 1985 and 40 in 1993. Here, $\beta_{\text {lin }}$ expresses the annual rate of change in the statistical association between social origin and destination -measured by the logarithm of the odds ratios- over the forty year period we are considering. Like model 4 , model 8 has the quality of being extremely parsimonious as it includes only one more parameter than the hypothesis of constant social fluidity. Finally, (2)-(8) will allow us to test the significance of a linear trend in the temporal change of the general level of social fluidity while (8)-(7) will test the hypothesis that this linear trend accurately expresses the changes in the strength of the origin-destination association which have occurred over the various surveys.

One question remains unanswered: if we assume that the analysis detects temporal variations in both the chances of immobility (models 3 to 6) and the general level of social fluidity (models 7 and 8 ) how can we discover whether these two trends co-existed, and if they did not, which supplanted the other and therefore better expresses the change in the survey data? A possible solution would be to combine the two trends in a single model. Let us now therefore consider model 9 which combines the linear trends in model 4 and model 8:

$$
\log \left(m_{i j t}\right)=\lambda+\lambda_{i}^{o}+\lambda_{j}^{D}+\lambda_{t}^{T}+\lambda_{i t}^{o T}+\lambda_{j t}^{D T}+a_{l i n} d_{i j t}+\left(1+\beta_{l i n} \text { year }\right) \psi_{i j}
$$


(4)-(9) will allow us to test the hypothesis that after introducing a linear trend in the chances of intergenerational immobility, adding another linear trend for the general level of social fluidity is significant. Similarly, (8)-(9) will test the reciprocal hypothesis that a linear trend affecting the chances of immobility remains after allowances have been made for a linear trend in social fluidity. Comparing the two results will provide the information needed to answer the previous question. Finally, the characteristics of model 6 can be combined with those of model 8 :

$$
\log \left(m_{i j t}\right)=\lambda+\lambda_{i}^{O}+\lambda_{j}^{D}+\lambda_{t}^{T}+\lambda_{i t}^{O T}+\lambda_{j t}^{D T}+\alpha_{i t} d_{i j}+\left(1+\beta_{l i n} \text { year }\right) \psi_{i j} \quad(\text { Model 10) }
$$

As model 6 achieves perfect fit for all the diagonal cells in the five mobility tables and introduces no restrictive hypothesis about temporal changes in the chances of immobility, (6)-(10) will test whether, in the case of mobile persons (i.e. those who have left their paternal class), a linear change in the general level of social fluidity has occurred over time. (29)

We now have ten models in order to conduct a general analysis of temporal change in social fluidity in France. Once each of these has been estimated using survey data, the likelihood ratio chi-square can be used to measure the distance between the expected and observed frequencies. This statistic will allow us to evaluate the proportion of the chi-square in the baseline model (that with perfect social fluidity at each date) which is explained by another, more complex, model. A second indicator which describes the quality of the fit is provided by the index of dissimilarity (delta) between the estimated and observed $5 \times 8 \times 8$ contingency tables. This measures the proportion of the total sample of individuals "who need to change cell" in order to transform the first table into the second. The lower the value of delta, the more faithfully the estimated model reproduces the observed data. Finally, the chi-square values can be used to perform a statistical test on the rejection or non-rejection of a model as with the difference between two nested models.

When these tests are conducted a difficulty, which has become prevalent in quantitative sociological research, is encountered. This results from the extremely large size of the samples involved -in this case more than 35,000 men and 18,000 women. It is a frequent occurrence for all, or almost all, the models to be rejected apart from that (saturated) model which describes the data perfectly but which fails to simplify them at all. Blindly following conventional statistical tests therefore leads to the inclusion of a large number of parameters in the models, some of which correspond to trivial effects which are very difficult to interpret. The same situation occurs with the comparison between models. It is possible, for example, that the difference between model 4 and model 6, which differ by 31 degrees of freedom in our analysis, is significant,

(29) We have in fact considered and tested all possible combinations of models 3 to 6 and models 7 and 8 (eight in all). They all lead clearly to the same conclusion, for both men and women. We have therefore retained only the two combinations whose interpretation strikes us as the most illuminating. 
while the goodness-of-fit with respect to the data is only very slightly improved by the inclusion of 31 additional parameters which are devoid of a structure allowing clear interpretation. A solution to: this difficult problem of model selection in the case of a large sample has been proposed by Raftery $(1986,1995)$ and has gradually come to be widely used. From a practical point of view Raftery's indicator, the Bayesian Information Criterion (BIC) favours adoption of a relatively parsimonious model by making a compromise between the goodness-of-fit of the model and the number of parameters it contains. In more precise terms it has been demonstrated that, in the Bayesian approach to statistical inference, a negative BIC means that the probability of the model in question is higher than that of the saturated model, given the data. Furthermore, it follows that in the case of two models, whether nested or not, the model with the most negative BIC value can be considered to be the most likely and therefore should be preferred. (30)

In the context of our analysis, where the comparison is to be made with the hypothesis of temporal invariance in the mobility regime, we can adopt the following decision rule: any model which adds one or more significant trends to the constant social fluidity model, but which has a less negative BIC value, should not be preferred to that model. However, it will be preferred to it each time the trend which is introduced turns out to be significant and the BIC obtained is more negative than that for the hypothesis of temporal invariance. In this situation, the trend in question will be considered to be sufficiently important to be taken into account and given a theoretical interpretation.

\section{Social fluidity has increased by $0.5 \%$ per year for forty years}

Table VIII gives the results of the general analysis conducted on male mobility tables. Although it is rejected by a conventional statistical test the constant social fluidity model misclassifies only $2.8 \%$ of the total male sample involved and eliminates almost $98 \%$ of the distance which separates the data from the baseline model -that of perfect fluidity at each date. Furthermore, the invariance model has a very high negative BIC value $(-1654)$ and therefore appears to have considerable potential for describing social fluidity - or the inequality of social opportunity- in France between 1953 and 1993.

However, if we consider models which permit a change over time in the chances of intergenerational immobility, we can see, from the parameters estimated using model 3 , that this is subject to a steady fall which can be described, without any important loss of information, by a linear trend. Model 4 therefore reveals a highly significant general trend towards a weakening of

(30) The BIC is calculated with the following formula: chi-square-(df) $\operatorname{LogN}$, where df is the number of degrees of freedom in the model and $\mathbf{N}$ is the sample size. In the long chapter in Sociological Methodology 1995 which he devotes to the Bayesian model selection approach, Raftery states that a 6 to 10 point difference between the BIC of two models amounts to strong evidence (and a difference of more than ten to very strong evidence) in favour of the model with the lower BIC (1995, p. 139, Table 6). 
the chances of immobility and, as its BIC value is considerably less than that of the invariance model $(-1670)$, should be preferred to it. Beyond this model, the linear and non-linear variations in the chances of immobility among the different classes are also significant, but as the BIC value of these hypotheses is poorer, of models 3 to 6 , model 4 should still be preferred.

As regards variation in the general level of social fluidity, the UNIDIFF model (model 7) reveals a steady reduction in the strength of the link between social origins and destinations. If $\beta$ is set at 1 for 1953 , its value falls to 0.806 in 1993, which indicates an increase in social fluidity of about $20 \%$ over four decades. Once again, this change can be considered, with negligible loss of information, as a highly significant linear trend. Because of its high BIC value $(-1679)$, the UNIDIFF model with a linear trend (model 8) should therefore be preferred to the invariance model. It leads to the conclusion, $\beta_{l i n}$ being equal to -0.0046 , that social fluidity has increased by $0.5 \%$ per year during the whole of our study period.

Finally, bringing together, in model 9, the two trends which have been revealed, once more leads to a description of the change which, on the basis of the BIC value, is to be preferred to the temporal invariance hypothesis and furthermore allows us to choose between the two trends which are involved. Adding a linear trend to the general level of social fluidity after having added a similar trend to the chances of immobility leads to a significant improvement in fit (the difference between models 4 and 9) but the reverse is not true (the difference between models 8 and 9). The existence of a general change in social fluidity over and above the variation in the chances of immobility is again confirmed by model 10: this trend, estimated solely on the basis of the individuals who have left their father's social class, is significant at the one per thousand level and, as $\beta_{l i n}$ is equal to -0.0060 , is no weaker than that found for the entire mobility table. Finally, on the basis of these findings it is the UNIDIFF model with a linear trend (model 8) which best describes the change which has occurred; besides this, of all the models we have considered it is the one with the most negative BIC ${ }^{(31)}$.

The same general analysis, performed on the mobility tables for women, gives the results in Table IX. No detailed commentary is required, as a careful examination will confirm that the conclusions about female mobility are identical to those about male mobility. Here too, on the grounds of their BIC value, three models (the same ones as before) are to be preferred to the temporal invariance model. Once again it is the UNIDIFF model with an added linear trend (model 8) which should finally be selected after a similar examination to

(31) John Goldthorpe has drawn our attention to the fact that the validity of the BIC statistic is not universally accepted (see in particular Weakliem, 1992, pp. 171-173). We would like to state that we feel the context in which BIC was first proposed seems to correspond with our research, i.e. a situation where the problem is not so much to select the true model but that which provides the most information about the real world (Hagenaars, 1990, pp. 66-68; Vermunt, 1997, p. 22). Furthermore, another frequently used indicator -the Akaike information criterion- also leads us to prefer, for both men and women, model 8 to the constant social fluidity model and models 3,4 and 9. 
$\operatorname{Men}(N=35,741)$

\begin{tabular}{|c|c|c|c|c|c|c|c|}
\hline Model & $\begin{array}{l}\text { Degrees of } \\
\text { freedom }\end{array}$ & & Chi-square & Test & Delta $(\%)$ & $\begin{array}{l}\% \text { of model } 1 \\
\text { chi-square } \\
\text { accounted for }\end{array}$ & BIC \\
\hline 1 - Perfect social fluidity at each date & 245 & & 17340.758 & $\mathrm{p}<.001$ & 25.6 & - & 14772.2 \\
\hline 2 - Constant social fluidity & 196 & & 401.258 & $\mathrm{p}<.001$ & 2.8 & 97.7 & -1653.6 \\
\hline \multicolumn{8}{|l|}{ Change in the chances of immobility } \\
\hline $\begin{array}{l}3 \text { - Change which is common to all classes } \\
\text { and specific to the year }\end{array}$ & 192 & & 368.240 & $\mathrm{p}<.001$ & 2.6 & 97.9 & -1644.7 \\
\hline 4 - Linear trend common to all classes & 195 & & 374.079 & $\mathrm{p}<.001$ & 2.7 & 97.8 & -1670.3 \\
\hline Difference $(2)-(4)$ & & 1 & 27.179 & $\mathrm{p}<.001$ & & & \\
\hline Difference $(4)-(3)$ & & 3 & 5.839 & $\mathrm{~ns}$ & & & \\
\hline 5 - Linear trend specific to each class & 188 & & 336.411 & $\mathrm{p}<.001$ & 2.5 & 98.1 & -1634.6 \\
\hline Difference $(4)-(5)$ & & 7 & 37.668 & $\mathrm{p}<.001$ & & & \\
\hline $\begin{array}{l}6 \text { - Change which is specific to each class } \\
\text { and to each date }\end{array}$ & 164 & & 270.364 & $\mathrm{p}<.001$ & 1.9 & 98.4 & -1449.0 \\
\hline Difference $(5)-(6)$ & & 24 & 66.047 & $\mathrm{p}<.001$ & & & \\
\hline \multicolumn{8}{|c|}{ Change in the general level of social fluidity } \\
\hline 7 - Uniform difference & 192 & & 364.810 & $\mathrm{p}<.001$ & 2.7 & 97.9 & -1648.1 \\
\hline 8 - Uniform difference with linear trend & 195 & & 365.615 & $\mathrm{p}<.001$ & 2.7 & 97.9 & -1678.8 \\
\hline Difference $(2)-(8)$ & & 1 & 35.643 & $\mathrm{p}<.001$ & & & \\
\hline Difference $(8)-(7)$ & & 3 & 0.805 & $\mathrm{~ns}$ & & & \\
\hline \multicolumn{8}{|c|}{ Change in the chances of immobility and the general level of social fluidity } \\
\hline 9 - Combination of models 4 and 8 & 194 & & 364.342 & $\mathrm{p}<.001$ & 2.7 & 97.9 & -1669.6 \\
\hline Difference $(4)-(9)$ & & 1 & 9.737 & $\mathrm{p}<.01$ & & & \\
\hline Difference $(8)-(9)$ & & 1 & 1.273 & $\mathrm{~ns}$ & & & \\
\hline $10-$ Combination of models 6 and 8 & 163 & & 254.580 & $\mathrm{p}<.001$ & 1.9 & 98.5 & -1454.3 \\
\hline Difference $(6)-(10)$ & & 1 & 15.784 & $\mathrm{p}<.001$ & & & \\
\hline
\end{tabular}


FQP surveys of 1970, 1977, 1985 and 1993 only $(\mathrm{N}=32,258)$

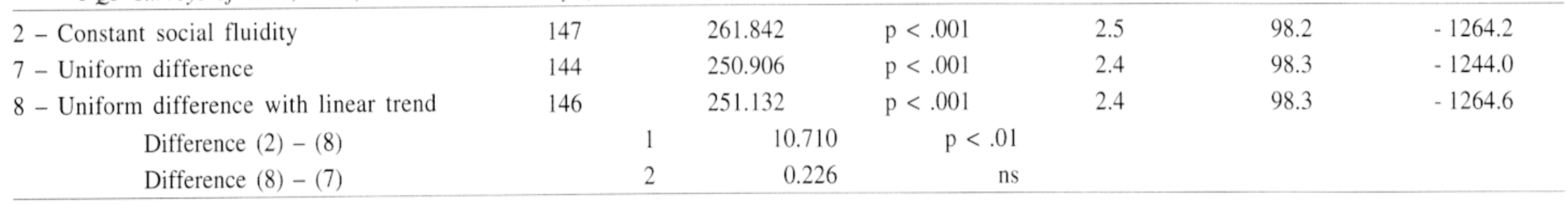

\begin{tabular}{|c|c|c|c|c|c|}
\hline Model & \multicolumn{5}{|c|}{ Estimated parameters } \\
\hline $\begin{array}{l}3 \text { - Change which is common to all classes } \\
\text { and specific to the year }\end{array}$ & $\begin{array}{l}\alpha_{1953}=0(\text { reference }) \\
\alpha_{1985}=-0.269^{* * * *}\end{array}$ & \multicolumn{2}{|c|}{$\begin{array}{l}\alpha_{1970}=-0.201 * * * \\
\alpha_{1993}=-0.276 * * *\end{array}$} & \multicolumn{2}{|c|}{$a_{1977}=-0.248^{* * *}$} \\
\hline 4 - Linear trend common to all classes & \multirow{2}{*}{\multicolumn{3}{|c|}{$a_{\text {lin }}=-0.0067 * * *$}} & \multirow{5}{*}{$\beta_{1985}=0.851$} & \multirow{5}{*}{$\beta_{1993}=0.806$} \\
\hline 7 - Uniform difference & & $\beta_{1970}=0.905$ & $\beta_{1977}=0.872$ & & \\
\hline 8 - Uniform difference with linear trend & $\beta_{\operatorname{lin}}=-0.0046$ & & & & \\
\hline 9 - Combination of models 4 and 8 & $\alpha_{\text {lin }}=-0.0020$ & $\beta_{\text {lin }}=-0.0037$ & & & \\
\hline $10-$ Combination of models 6 and 8 & $\beta_{l i n}=-0.0060$ & & & & \\
\hline \multicolumn{6}{|c|}{ FQP surveys of $1970,1977,1985$ and 1993 only $(\mathrm{N}=32,258)$} \\
\hline $\begin{array}{l}7 \text { - Uniform difference } \\
8 \text { - Uniform difference with linear trend }\end{array}$ & $\begin{array}{l}\beta_{1970}=1.000 \\
\beta_{l i n}=-0.0042\end{array}$ & $\beta_{1977}=0.967$ & $\beta_{1985}=0.944$ & $\beta_{1993}=0.897$ & \\
\hline
\end{tabular}

***: $\mathrm{p}<.001$; the software does not compute the standard error on the parameters of a log-multiplicative model (models 7 to 10 ) 
Women $(N=18,484)$

\begin{tabular}{|c|c|c|c|c|c|c|c|}
\hline Model & $\begin{array}{l}\text { Degrees of } \\
\text { freedom }\end{array}$ & & Chi-square & Test & Delta $(\%)$ & $\begin{array}{l}\% \text { of model } 1 \\
\text { chi-square } \\
\text { accounted for }\end{array}$ & $\mathrm{BIC}$ \\
\hline 1 - Perfect social fluidity at each date & 245 & & 6964.391 & $\mathrm{p}<.001$ & 22.5 & - & 4557.3 \\
\hline 2 - Constant social fluidity & 184 & & 341.859 & $\mathrm{p}<.001$ & 3.6 & 95.1 & -1465.9 \\
\hline \multicolumn{8}{|l|}{ Change in the chances of immobility } \\
\hline $\begin{array}{l}3 \text { - Change which is common to all classes } \\
\text { and specific to the year }\end{array}$ & 180 & & 316.361 & $\mathrm{p}<.001$ & 3.5 & 95.5 & -1452.1 \\
\hline 4 - Linear trend common to all classes & 183 & & 324.174 & $\mathrm{p}<.001$ & 3.6 & 95.3 & -1473.7 \\
\hline Difference $(2)-(4)$ & & 1 & 17.685 & $\mathrm{p}<.001$ & & & \\
\hline Difference $(4)-(3)$ & & 3 & 7.813 & $\mathrm{p}<.10$ & & & \\
\hline 5 - Linear trend specific to each class & 176 & & 310.536 & $\mathrm{p}<.001$ & 3.5 & 95.5 & -1418.6 \\
\hline Difference $(4)-(5)$ & & 7 & 13.638 & $\mathrm{p}<.10$ & & & \\
\hline $\begin{array}{l}6 \text { - Change which is specific to each class } \\
\text { and to each date }\end{array}$ & 152 & & 240.203 & $\mathrm{p}<.001$ & 2.7 & 96.6 & -1253.1 \\
\hline Difference $(5)-(6)$ & & 24 & 70.333 & $\mathrm{p}<.001$ & & & \\
\hline \multicolumn{8}{|l|}{ Change in the general level of social fluidity } \\
\hline 7 - Uniform difference & 180 & & 312.914 & $\mathrm{p}<.001$ & 3.5 & 95.5 & -1455.5 \\
\hline 8 - Uniform difference with linear trend & 183 & & 320.250 & $\mathrm{p}<.001$ & 3.5 & 95.4 & -1477.7 \\
\hline Difference $(2)-(8)$ & & 1 & 21.609 & $\mathrm{p}<.001$ & & & \\
\hline Difference $(8)-(7)$ & & 3 & 7.336 & $\mathrm{p}<.10$ & & & \\
\hline \multicolumn{8}{|c|}{ Change in the chances of immobility and the general level of social fluidity } \\
\hline 9 - Combination of models 4 and 8 & 182 & & 318.448 & $\mathrm{p}<.001$ & 3.5 & 95.4 & -1469.6 \\
\hline Difference $(4)-(9)$ & & 1 & 5.726 & $\mathrm{p}<.02$ & & & \\
\hline Difference $(8)-(9)$ & & 1 & 1.802 & $\mathrm{~ns}$ & & & \\
\hline $10-$ Combination of models 6 and 8 & 151 & & 234.761 & $\mathrm{p}<.001$ & 2.7 & 96.6 & -1248.8 \\
\hline Difference $(6)-(10)$ & & 1 & 5.442 & $\mathrm{p}<.02$ & & & \\
\hline
\end{tabular}




\begin{tabular}{|c|c|c|c|c|c|c|c|}
\hline \multicolumn{8}{|c|}{ FQP surveys of $1970,1977,1985$ and 1993 only $(\mathrm{N}=16,477)$} \\
\hline 2 - Constant social fluidity & 138 & & 239.197 & $\mathrm{p}<.001$ & 3.3 & 95.8 & -1100.7 \\
\hline 7 - Uniform difference & 135 & & 221.340 & $\mathrm{p}<.001$ & 3.0 & 96.1 & -1089.5 \\
\hline 8 - Uniform difference with linear trend & 137 & & 228.448 & $\mathrm{p}<.001$ & 3.1 & 96.0 & -1101.8 \\
\hline Difference $(2)-(8)$ & & 1 & 10.749 & $\mathrm{p}<$ & & & \\
\hline Difference (8) - (7) & & 2 & 7.108 & $\mathrm{p}<$ & & & \\
\hline
\end{tabular}

The number of degrees of freedom for each model can be adjusted in order to take account of zeros in the observed margin (OD) (Bishop, Fienberg and Holland, 1975, pp. 115-119).

\begin{tabular}{|c|c|c|c|c|c|}
\hline \multirow{2}{*}{$\begin{array}{l}\text { Model } \\
3-\text { Change which is common to all classes } \\
\text { and specific to the year }\end{array}$} & \multicolumn{5}{|c|}{ Estimated parameters } \\
\hline & $\begin{array}{l}a_{1953}=0 \text { (referenc } \\
a_{1985}=-0.282 * * *\end{array}$ & $\begin{array}{l}a_{1970}= \\
a_{1993}=\end{array}$ & $\begin{array}{l}-0.201 * * \\
-0.302 * * *\end{array}$ & $a_{1977}=-0.330 * * *$ & \\
\hline 4 - Linear trend common to all classes & $a_{\text {lin }}=-0.0075^{* * *}$ & & & & \\
\hline 7 - Uniform difference & $\beta_{1953}=1.000$ & $\beta_{1970}=0.959$ & $\beta_{1977}=0.841$ & $\beta_{1985}=0.876$ & $\beta_{1993}=0.783$ \\
\hline 8 - Uniform difference with linear trend & $\beta_{\text {lin }}=-0.0052$ & & & & \\
\hline 9 - Combination of models 4 and 8 & $\alpha_{l i n}=-0.0030$ & $\beta_{\text {lin }}=-0.0039$ & & & \\
\hline $10-$ Combination of models 6 and 8 & $\beta_{\text {lin }}=-0.0054$ & & & & \\
\hline \multicolumn{6}{|c|}{ FQP surveys of $1970,1977,1985$ and 1993 only $(\mathrm{N}=16,477)$} \\
\hline $\begin{array}{l}7 \text { - Uniform difference } \\
8 \text { - Uniform difference with linear trend }\end{array}$ & $\begin{array}{l}\beta_{1970}=1.000 \\
\beta_{l i n}=-0.0063\end{array}$ & $\beta_{1977}=0.878$ & $\beta_{1985}=0.917$ & $\beta_{1993}=0.817$ & \\
\hline
\end{tabular}

$* *: p<.01 ; * * *: p<.001$; the software does not compute the standard error on the parameters of a log-multiplicative model (models 7 to 10 ) 
that conducted for men. Lastly, the scale of the steady trend towards increasing social fluidity is the same as that measured for men: the parameter $\beta_{\text {lin }}$ is equal to -0.0052 and expresses the fact that the annual rate of the reduction in the strength of the association between the social destination of women and that of their fathers is $0.5 \%$. In fact, the only difference between the results of the tables for women and the tables for men concerns the most general form of the UNIDIFF model (model 7): a non-linearity occurs at the changeover point between the three tables based on the CSP version of our class schema and those which use the $P C S$ version, $\beta_{1985}$ being greater than $\beta_{1977}$. We are however inclined to minimize the importance of this irregularity and interpret it as an artefact resulting from a change in coding as no equivalent phenomenon was apparent when we conducted the analysis described above with a uniform schema for the period 1977-93. The presence and direction of this artefact would seem to indicate that when a single analysis is applied to tables which use slightly different schemas there is a slight underestimation of the scale of the change which has occurred over the forty year period. This view is also supported by the comparison, for men and women, between the estimate from the general analysis (which was that there has been a reduction of about $20 \%$ in the strength of the link) and the estimate from a separate analysis of the two periods 1953-77 and 1977-93 (which was that a reduction of about $25 \%$ has occurred). ${ }^{(32)}$

Three important conclusions emerge from our general analysis. Firstly, a particularly simple model which differs from the temporal invariance model only in that an additional parameter is estimated is closer than that model to French mobility tables for both men and women over our forty year period. It reveals a unidirectional shift in French society towards increased fluidity, i.e. a steady reduction in inequality of social opportunity, and estimating other models confirms the robustness and scale of this change. Before concluding this paper, we should therefore use appropriate techniques to show the additional social circulation which has resulted from this trend. Secondly, previous research on the period 1953-77 (Goldthorpe and Portocarero, 1981; Thélot, 1982; Vallet, 1991, 1992) interpret what was in fact just the most visible part of a more general opening up of the mobility regime as a reduction in solely the chances of intergenerational immobility. When this research was carried out this opening up was barely detectable as the tools required to reveal it, in particular the UNIDIFF model, were not available. Thirdly, there are grounds for concern that the 1953 data play an important role in establishing the observed trend and therefore distort our view of the period in question. Research has already suggested (Thélot, 1983) that the 1953 data, which are the oldest, may not be very comparable with the others. For our investigation

(32) Finally, proof of this can be obtained by estimating the UNIDIFF model for the 1977 mobility tables in the CSP and PCS versions of our class schema. If we fix $\beta_{C s p}$ at 1 , the value of $\beta_{P C s}$ is 1.069 for women and 1.040 for men. The statistical association between social origin and destination therefore seems stronger in the PCS version. It follows that the scale of long-term change is slightly underestimated when mobility tables using both versions are mixed. 
at least, such fears are not justified: as Tables VIII and IX show, the size of the annual trend varies little for men and is even greater for women when only the 1970 to 1993 Formation - Qualification Professionnelle surveys are considered.

\section{A final confirmation using Goodman's log-multiplicative association model}

Following an approach which closely resembles that adopted by Robert Erikson and John Goldthorpe in The Constant Flux, we have thus identified a situation, for France, which these authors themselves considered as critical for the temporal invariance thesis of the intergenerational mobility regime. After applying the UNIDIFF model and that which permitted inter-cohort variation in the chances of immobility, Erikson and Goldthorpe stated that they would not test the constrained version of these models (that which features a monotonic change) but immediately add that if such a change appeared it would be unwise to discount it, even if the improvement in fit is not significant. ${ }^{(33)}$ It is precisely a change of this type, in addition with a high level of significance, which we have detected, for both men and women in France in the second half of the century.

Readers will remember that the research conducted by Ganzeboom, Luijkx and Treiman (1989) and Wong (1994) used the log-multiplicative association model proposed by Goodman (1979) and we shall now apply it to French data to obtain a final confirmation of our result. In the context of an analysis of intergenerational mobility, we can interpret a model of this type in the following terms: in the generation of fathers and that of sons and daughters, the social structure consists of a ladder for which we can simultaneously determine the order of the rungs and the distance between them. An advantage of this model is, therefore, that it is not based on any a priori hypothesis concerning the order of classes in the social structure, which appears as a product of the analysis. In fact, we do not intend to adopt this view of social structure as a total order and actually agree more with Erikson and Goldthorpe's view of a set of discrete classes between which only some partial orders can be determined. Thus, our use of Goodman's model will be "weak", i.e. we shall use it here purely as a statistical tool in order to test for one last time the robustness of our result. When applied to a set of tables from different dates, this model can be expressed, in its most general form, as follows:

$$
\log \left(m_{i j t}\right)=\lambda+\lambda_{i}^{o}+\lambda_{j}^{D}+\lambda_{t}^{T}+\lambda_{i t}^{o T}+\lambda_{j t}^{D T}+\phi_{t} \mu_{i t} \nu_{j t}
$$

(33) "Since we still do not test quite specifically for monotonic change, we show here for each of our nations both the improvement in fit produced by these models and the uniform- or diagonal-change parameters that are estimated for each cohort. Should the latter indicate monotonic change, it would be unwise to discount this, even if the improvement in fit falls short of significance." (Erikson and Goldthorpe, 1992, pp. 93-94). 
which implies that:

$$
\log (o d)=\phi_{i}\left(\mu_{i t}-\mu_{i^{\prime} t}\right)\left(\nu_{j t}-\nu_{j^{\prime} t}\right)
$$

The statistical association between social origins and destinations is therefore analyzed as three sets of parameters. The parameters $\mu_{i t}$ (or the scale of origin scores) express the position of class $i$ on the scale estimated for origin classes at date $t$. The parameters $\nu_{j t}$ (or the scale of destination scores) do the same with respect to the estimated scale, at the same date, for destination classes. Thus, and as is shown by the logarithm of the odds ratio, the greater the distance between the classes $i$ and $i^{\prime}$ and the classes $j$ and $j^{\prime}$ the less fair is the competition between individuals from the two origins to reach one rather than the other of the two destinations. In this context, the parameter $\phi_{t}$ provides a general measure of the strength of the link between origin and destination at date $t$.

In this form, Goodman's model fits the actual mobility data (whether from France or other countries) rather poorly as it does not reconstruct social immobility, which varies from one class to another, well. We therefore add a term $\gamma_{i} d_{i j}$ to the above expression, where $d_{i j}$ is equal to 1 when $i$ is equal to $j$ and 0 otherwise. The parameter $\gamma_{i}$ therefore expresses the propensity towards immobility -which is constant over time- of class $i$. In addition, it is possible to develop more highly constrained forms of Goodman's model (Becker and Clogg, 1989) and we shall assume here that the scales which are estimated for origin classes and destination classes do not change from one survey to another. If we thus concentrate on temporal change in the $\phi$ parameter only, we are able to estimate three different forms of the model. The first postulates that the different $\phi_{t}$ parameters are identical, i.e. the strength of the link between class of origin and class of destination is temporally invariant:

$$
\log \left(m_{i j t}\right)=\lambda+\lambda_{i}^{O}+\lambda_{j}^{D}+\lambda_{t}^{T}+\lambda_{i t}^{o T}+\lambda_{j t}^{D T}+\gamma_{i} d_{i j}+\phi \mu_{i} \nu_{j}
$$

The second allows heterogeneity among the $\phi_{t}$ parameters, i.e. a temporal change of any type in the strength of the link between social origin and destination:

$$
\log \left(m_{i j t}\right)=\lambda+\lambda_{i}^{o}+\lambda_{j}^{D}+\lambda_{i}^{T}+\lambda_{i t}^{o r}+\lambda_{j t}^{D T}+\gamma_{i} d_{i j}+\phi_{i} \mu_{i} \nu_{j} \text { (Model }
$$

The third imposes a linear trend on this temporal change (Wong, 1995):

$$
\log \left(m_{i j t}\right)=\lambda+\lambda_{i}^{O}+\lambda_{j}^{D}+\lambda_{t}^{T}+\lambda_{i t}^{o T}+\lambda_{j t}^{D T}+\gamma_{i} d_{i j}+\phi_{0}\left(1+\phi_{\text {lin }} \text { year }\right) \mu_{i} \nu_{j}
$$

where year is the quantitative variable defined above.

If we apply Goodman's model, which considers the association between social origin and destination in a very different form from the UNIDIFF model, our result would be precisely confirmed if, firstly, the $\phi_{t}$ parameters estimated 
using model 12 diminished regularly between 1953 and 1993; secondly, this change could be represented, without the loss of any important information, by the linear trend in model 13; thirdly, this linear trend was statistically significant and Goodman's model with a linear trend also had a BIC value which made it preferable to the invariance model (model 11). The results of our estimations are given in Table $X$.

These three predictions are accurately fulfilled, apart from a minor irregularity we have already seen, which is linked to the fact that for women $\phi_{1985}$ is higher rather than lower than $\phi_{1977 .}$ Once again, this seems to be related to the change in class schema between the two surveys. It is noteworthy that $\phi_{\text {lin }}$ takes on a value of -0.0080 for men and -0.0073 for women. This annual rate of change in the strength of the association between social origin and destination is very close to that estimated by Ganzeboom, Luijkx and Treiman (1989) with the same model -approximately one percent per year. It is exactly the same as that obtained by Wong (1994) for the United States between 1947 and 1986. It is, however, greater than that given by the UNIDIFF model with French data -about half a percent per year- but it would be unwise to revise our estimates upwards because, as the chi-square values show, Goodman's association model fits French mobility tables less well than the UNIDIFF model. This confirms the reservations expressed by Erikson and Goldthorpe (1992, p. 100) about association models which seem to overestimate the scale of change.

In short, a model which is very different from the one we applied at the outset confirms that social fluidity has risen continuously in France over four decades. Another important factor is that the same change can be observed in data other than those from the Formation - Qualification Professionnelle surveys, namely the 1982 and 1997 Emploi surveys. (34)

\section{The concrete effects of the reduction in the inequality of social opportunity}

According to the model which best expresses the change which has occurred in France over our forty year period, the intrinsic strength of the link between the social position which individuals occupy as a result of their employment and the class of origin has fallen at a rate of $0.5 \%$ per year, which is to say by $20 \%$ over the period as a whole. Expressed in these terms the

(34) While this paper was being written Michel Forsé estimated the UNIDIFF model using two father-son mobility tables from the 1982 and 1997 Emploi surveys. These tables dealt with men aged between 40 and 55 who were in the labour force and were constructed using the PCS one-digit schema $(\mathrm{N}=5,107$ for each table). The $\beta$ parameter was fixed at 1 in
1982 and took on a value of 0.92 in 1997 , which indicates an increase in social fluidity of $8 \%$ in 15 years, i.e. an annual rate of $0.5 \%$ again. Furthermore, this difference is significant at the ten percent level. The author would like to thank Michel Forse for making these results available to him (Forsé, 1998). 


\begin{tabular}{|c|c|c|c|c|c|c|}
\hline Model & Degrees of freedom & Chi-square & Test & Delta $(\%)$ & $\begin{array}{l}\% \text { of model } 1 \\
\text { chi-square } \\
\text { accounted for }\end{array}$ & BIC \\
\hline \multicolumn{7}{|l|}{$\operatorname{Men}(\mathrm{N}=35,741)$} \\
\hline $11-$ Temporal invariance of $\phi$ & 224 & 939.527 & $\mathrm{p}<.001$ & 4.4 & 94.6 & -1408.9 \\
\hline $12-$ Heterogeneity of $\phi$ & 220 & 895.752 & $\mathrm{p}<.001$ & 4.3 & 94.8 & -1410.7 \\
\hline $\begin{array}{l}13 \text { - Linear trend of } \phi \\
\text { Difference }(11)-(13) \\
\text { Difference }(13)-(12)\end{array}$ & 223 & $\begin{array}{r}899.698 \\
39.829 \\
3.946 \\
\end{array}$ & $\begin{array}{r}\mathrm{p}<.001 \\
\mathrm{p}<\end{array}$ & $\begin{array}{r}.001 \\
\mathrm{~ns}\end{array}$ & 94.8 & -1438.2 \\
\hline \multicolumn{7}{|l|}{ Women $(\mathrm{N}=18,484)$} \\
\hline 11 - Temporal invariance of $\phi$ & 224 & 574.787 & $\mathrm{p}<.001$ & 5.3 & 91.7 & -1625.9 \\
\hline $12-$ Heterogeneity of $\phi$ & 220 & 554.428 & $\mathrm{p}<.001$ & 5.2 & 92.0 & -1607.0 \\
\hline $\begin{array}{l}13 \text { - Linear trend of } \phi \\
\text { Difference }(11)-(13) \\
\text { Difference }(13)-(12)\end{array}$ & 223 & $\begin{array}{r}560.331 \\
14.456 \\
5.903 \\
\end{array}$ & $\begin{array}{r}\mathrm{p}<.001 \\
\mathrm{p}<\end{array}$ & $\begin{array}{r}.001 \\
\text { ns }\end{array}$ & 92.0 & -1630.6 \\
\hline Model & \multicolumn{6}{|c|}{ Estimated parameters } \\
\hline \multicolumn{7}{|l|}{$\operatorname{Men}(\mathrm{N}=35,741)$} \\
\hline 11 - Temporal invariance of $\phi$ & $\phi=7.651$ & & & & & \\
\hline $\begin{array}{l}12 \text { - Heterogeneity of } \phi \\
13 \text { - Linear trend of } \phi\end{array}$ & $\begin{array}{l}\phi_{1953}=9.672 \\
\phi_{0}=9.300\end{array}$ & $\begin{array}{l}\phi_{1970}=7.830 \\
\phi_{\text {lin }}=-0.0080\end{array}$ & $\phi_{1977}=7.396$ & $\phi_{1985}=7.212$ & $\phi_{1993}=6.141$ & \\
\hline \multicolumn{7}{|l|}{ Women $(\mathrm{N}=18,484)$} \\
\hline $\begin{array}{l}11 \text { - Temporal invariance of } \phi \\
12 \text { - Heterogeneity of } \phi \\
13 \text { - Linear trend of } \phi\end{array}$ & $\begin{array}{l}\phi=8.409 \\
\phi_{1953}=11.239 \\
\phi_{0}=10.835\end{array}$ & $\begin{array}{l}\phi_{1970}=10.391 \\
\phi_{\text {lin }}=-0.0073\end{array}$ & $\phi_{1977}=8.293$ & $\phi_{1985}=8.862$ & $\phi_{1993}=7.842$ & \\
\hline
\end{tabular}

The software used does not compute the standard error on the parameters of a log-multiplicative model (models 11 to 13). 
change is abstract, and we shall now attempt to see in concrete terms the scale of the change which has resulted from the opening up of the intergenerational mobility regime. An increase in social fluidity means that some men and women are today in social positions which they would not have held if the mobility regime in France had remained the same as it was in the middle of the century. What we will now do is make visible the additional circulation mobility which has resulted from this slight but continuous reduction in social inequality.

We shall start with the mobility tables estimated using the UNIDIFF model with a linear trend. These tables have been constructed from a sample. Firstly, by multiplying by an appropriate factor we can adjust the 1993 table in accordance with the margins which characterize French society at that date, i.e. the socio-occupational distribution of French men (or women) aged between 35 and 59 who are employed and that of their fathers. We shall refer to this table as T. It differs little from the real table for 1993 (that which has been directly extrapolated from the survey data) as the model provides a reasonably faithful representation of the period in question. We shall now turn to the estimated mobility table for 1953. If we apply the margins which characterize French society in 1993 to this we obtain a counterfactual table showing what would have been the case in 1993 if the French mobility regime had remained exactly the same as it was during the early fifties. In order to do this we simply need to use an algorithm whose essential feature is that it conserves the odds ratios, i.e. the structure of mobility, of the estimated table. ${ }^{(35)}$ If we refer to the resulting table as $T$ ' we merely need to compute for each cell the difference $T-T$ ' in order to show the circulation mobility which occurred in 1993 solely as a result of the opening up of the intergenerational mobility regime. These differences, rounded to the nearest thousand, are given in Table XI. Although they provide us with a plausible representation of the increase in social fluidity, they are subject to a degree of uncertainty because the calculation is entirely based on estimations from a model. It is therefore important not to ascribe too much importance to small frequencies. It would also be desirable to check that the resulting pattern is robust for specific populations.

Let us start with the first table, which deals with French men between the ages of 35 and 59 who were in the workforce in 1993. Because of the way it has been constructed, the sum of the cells in the differences table is nil for each line and each column (apart from distortions caused by rounding). The circulation mobility which results just from the opening up of the mobility regime can be described as follows: some of the men of a given social origin do not occupy certain positions but others, which therefore cannot be held by men from a different class. The opening up of the mobility regime is therefore similar to a zero-sum game as the positions acquired by some individuals are lost by others. What do we observe under these circumstances?

(35) This algorithm has already been described in note 8 of this paper. 


\section{Revue française de sociologie}

\section{TABLE XI. - Circulation mobility caused by the opening up of the intergenerational mobility regime (frequencies in thousands)}

Effect of opening up between 1953 and 1993 (Working French men aged between 35 and 59)

Father

Son $\quad \begin{array}{lllllllll}\text { Total } \\ \text { (thousand }\end{array}$

1. Farmer or smallholder

2. Farm worker

3. Artisan, small shopkeeper

$\begin{array}{cccccccc}-28 & -1 & +1 & +4 & +14 & +12 & 0 & -1 \\ +3 & -4 & 0 & +1 & +3 & +3 & 0 & -7 \\ +5 & +1 & -34 & -2 & +4 & +4 & +2 & +21 \\ +1 & 0 & +2 & -14 & -4 & +4 & +2 & +8 \\ +2 & 0 & +6 & -2 & -31 & +5 & +6 & +14 \\ +1 & 0 & +6 & 0 & -15 & -14 & +3 & +20 \\ +4 & +1 & +5 & +3 & -4 & -18 & -7 & +17 \\ +12 & +3 & +14 & +10 & +34 & +3 & -6 & -71\end{array}$

4. Head of undertaking, large shopkeeper, liberal profession

5. Higher-grade professional

6. Middle-grade professional

7. Non-manual worker, service worker, other employee

8. Supervisor of manual workers, manual worker

(346) $(50)(674)(281)(1,145)(1,302)(684)(2,456)$

Total (thousands)

Interpretation: In the population of French men between the ages of 35 and 59 who were in the workforce in 1993, 2,713,000 were the sons of manual workers or their supervisors. As a result of the increase in social fluidity between 1953 and 1993, 71,000 are not manual workers and 34,000 of these are higher-grade professionals.

Effect of opening up between 1953 and 1993 (Working French women aged between 35 and 59)

Father

Daughter $\quad 1 \quad \begin{array}{lllllllll}\text { Total } \\ \text { (thousands) }\end{array}$

1. Farmer or smallholder

2. Farm worker

3. Artisan, small shopkeeper

\begin{tabular}{lccccccc|l}
-27 & 0 & -2 & +1 & +10 & +14 & +6 & -2 & $(945)$ \\
+2 & -1 & 0 & 0 & +2 & +4 & -5 & -3 & $(198)$ \\
+5 & 0 & -12 & 0 & +1 & -6 & +5 & +7 & $(641)$ \\
+1 & 0 & 0 & -3 & -5 & -1 & +6 & +1 & $(142)$ \\
+2 & 0 & +3 & -1 & -28 & -4 & +23 & +5 & $(460)$ \\
+1 & 0 & +2 & 0 & -5 & -15 & +12 & +5 & $(406)$ \\
+2 & 0 & +1 & +1 & +3 & -9 & -5 & +7 & $(631)$ \\
+13 & +1 & +6 & +3 & +22 & +17 & -41 & -20 & $(1,977)$ \\
$(263)(18)(330)(67)(556)(1,241)(2,270)(654)$ & $(5,399)$
\end{tabular}

4. Head of undertaking, large shopkeeper, liberal profession

5. Higher-grade professional

6. Middle-grade professional

7. Non-manual worker, service worker, other employee

8. Supervisor of manual workers, manual worker

Total (thousands)

(263) (18) (330) (67) (556) (1,241) (2,270) (654)

Interpretation: In the population of French women between the ages of 35 and 59 who were in the workforce in 1993, 1,977,000 were the daughters of manual workers or their supervisors. As a result of the increase in social fluidity between 1953 and 1993, 20,000 are not manual workers and 41,000 are not non-manual workers; amongst these women, 22,000 are higher-grade professionals and 17,000 are middle-grade professionals. 
Effect of opening up between 1977 and 1993

(French and foreign men aged between 30 and 59, currently or formerly in the workforce) (PCS one-digit schema)

\begin{tabular}{|c|c|c|c|c|c|c|c|}
\hline Father & 1 & 2 & 3 & 4 & 5 & 6 & $\begin{array}{c}\text { Total } \\
\text { (thousands) }\end{array}$ \\
\hline 1. Farmer or smallholder & -27 & +3 & +15 & +14 & +3 & -8 & $(1,646)$ \\
\hline $\begin{array}{l}\text { 2. Artisan, shopkeeper, } \\
\text { head of undertaking }\end{array}$ & +6 & -35 & 0 & +2 & +3 & +23 & $(1,338)$ \\
\hline $\begin{array}{l}\text { 3. Professional, higher-grade } \\
\text { intellectual profession }\end{array}$ & +3 & +7 & -43 & +10 & +6 & +17 & $(872)$ \\
\hline 4. Intermediate profession & +2 & +5 & -15 & -20 & 0 & +29 & $(1,228)$ \\
\hline 5. Non-manual worker & +3 & +4 & 0 & -14 & -12 & +19 & $(1,210)$ \\
\hline 6. Manual worker & +14 & +16 & +43 & +8 & -1 & -79 & $(4,340)$ \\
\hline Total (thousands) & $(436)$ & $(1,023)$ & $(1,749)$ & $(2,368)$ & $(1,062$ & $(3,995)$ & $(10,633)$ \\
\hline
\end{tabular}

Interpretation: In the population of French and foreign men between the ages of 30 and 59 who were or had formerly been in the workforce in 1993, 4,340,000 were the sons of manual workers. As a result of the increase in social fluidity between 1977 and 1993, 79,000 are not manual workers and 43,000 of these are higher-grade professionals.

The movement stems from the reduction in immobility. The diagonal contains only negative frequencies, although these are also present, less frequently, in other parts of the table. Social destinations vary according to class of origin, but in all cases there is a reduction in the inequality of opportunity. Those sons of farmers or smallholders who are no longer on the land as a result of the increase in social fluidity have tended to become higher-grade or middle-grade professionals. The same applies to the sons of agricultural workers who have not followed in their father's footsteps and have not become manual workers. Some children of the self-employed petty bourgeoisie have spread out to different social classes purely as a result of the opening up of the mobility regime: these have above all joined the working class, which is a sign of the weakening of their class of origin. It has become less certain that the sons of higher-grade and middle-grade professionals will remain in their father's social class, and children of lower-grade professionals are also less likely to rise in the social hierarchy. Finally, 71,000 sons of manual workers or their supervisors have left the working class purely because of the opening up of the intergenerational mobility regime, and 34,000 of these have become higher-grade professionals. Altogether, of the population in question, we can estimate that almost 265,000 (or $3.8 \%$ of the total number) are in positions which they would not have held if there had been no increase in social fluidity over our forty year period. While it is true that this proportion is not very large, it could not be described as negligible or insignificant.

If we perform the same calculation separately for the population of women aged between 35 and 59 in employment in 1993, we obtain the second table. The similarity between the pattern which emerges and that we have just 
described is striking, which attests to the consistency of our result. The only qualification we need to make is that non-manual workers, who account for a large proportion of the female workforce, are more frequently affected by changes in social position. Here, 20,000 daughters of manual workers or their supervisors did not become manual workers themselves and 41,000 did not become non-manual workers purely as a result of the change which took place in France between 1953 and 1993. Of these women, 22,000 have become higher-grade professionals and 17,000 have become middle-grade professionals. Altogether, we can estimate that in 1993 the social destination of 195,000 women (or $3.6 \%$ of the total number) has been altered in this way.

Because the increase in social fluidity has occurred as a continuous trend, we can assess its effects over a period of less than four decades. If we take 1977-93, we can examine the changes which have occurred in France over what is roughly the last twenty years. There are several advantages to be gained by focusing our analysis on the population studied by Goux and Maurin (1997a, 1997b), namely French and foreign men aged between 30 and 59 , currently or formerly in the workforce. Firstly, this adds almost four million men to the first table, considerably broadening the spectrum of analysis. Secondly, it allows us to use the PCS one-digit class schema as has become customary. Finally, the fit achieved for these data for 1977,1985 and 1993 with the UNIDIFF model including a linear trend is remarkably good. ${ }^{(36)}$ The social circulation resulting from the opening up of the intergenerational mobility regime between 1977 and 1993 still takes the same form. In 1993 it affected 255,000 men, or $2.4 \%$ of the total population. This percentage is lower than before because of the shorter time interval.

The foregoing assessments are all based on estimates from a model. It is therefore desirable to compare them with others which are based solely on real data. Let us take the observed mobility table for the 1977 survey with the PCS one-digit class schema. We can apply the 1993 margins to this and thus calculate the additional social circulation caused by change in the mobility regime. Two main findings emerge if we compare this model-free assessment to the previous one. Firstly, the effect of the opening up of the intergenerational mobility regime is greater in the new assessment $(400,000$ men or $3.8 \%$ of the total population are affected); the fact that the model we have used underestimates the scale of the change is once more apparent. Secondly, the model-free assessment reveals again, in amplified form, the most significant features of Table XI: a reduction of immobility among wage earners and salaried employees, more sons of farmers and smallholders who join the professional or intermediate classes, an increased interchange between the category of professionals and higher-grade intellectual professions and the category of manual workers. Similar appraisals for both men and women for the period

(36) For 49 degrees of freedom chi-square is equal to 62.635 , delta is $1.2 \%$, the BIC value is -448.1 as opposed to -437.5 for the constant social fluidity model, $\beta_{l i n}$ is estimated at -0.0081 . The model is therefore rejected at the ten percent level, but not at the five percent level, which is remarkable in view of the size of the sample $(\mathrm{N}=33,602)$. These results can be compared with those in Table VII. 
1953-93 add further support to these two observations even though they must be viewed with a certain amount of caution in view of the change in schema which occurred during the period.

So, if we modify the title of the seminal book in which Robert Erikson and John Goldthorpe examined social mobility in industrial societies, the Flux in France has not been constant. In La Seconde Révolution française, Henri Mendras, describing the increase in net mobility revealed by the work of Claude Thélot, wrote: "In the last forty years French society has become visibly less rigid." (1988, p. 57). John Goldthorpe, recognizing that a change could have occurred in the post-war period, answered that it had not however reached the scale implied by the comments made by Mendras (1995, p. 69). We know now that this decrease in rigidity has been real and continuous, but to qualify it as visible was no doubt an exaggeration as the change has taken place at a rate of less than one percent per year and could therefore not be clearly perceived by even an informed observer. ${ }^{(37)}$ The quality of the description provided by the constant fluidity model on its own indicates that social inequality has remained essentially unchanged in form, but its level has fallen. This justifies our use of the term slow erosion which we feel most accurately expresses the change. ${ }^{(38)}$ In the fairly near future it could be therefore possible to extend this work by introducing the core model described by John Goldthorpe in his 1995 paper into the study of French mobility tables over four decades. This would enable us to investigate which aspects of the mobility regime have been modified. However, until the driving forces behind it have been identified, the fact that such a change has occurred in France since the middle of the century in no way allows us to state that the same is true for another society or that the movement will continue.

Falsifying temporal invariance in the intergenerational mobility regime, as we believe we have for France in this paper, means that we must recognize that the level of inequality of opportunity which exists within a modern soci-

(37) Besides, if the change had been so visible the scientific controversy would have been less intense.

(38) Surprised at their inability to reveal a change in the mobility regime between 1977 and 1993, D. Merllié and J. Prévot concluded in the following terms: "If observed mobility (i.e. the flow between different categories) undergoes major changes simultaneously with the social structure (the relative sizes of the categories), one would expect the mobility regime (the closeness or distance between categories which is expressed by movement between them) to be affected too, as a result of changes in the relative social value of the different categories." (1997, pp. 56-58). On the basis of this statement (see also Merllié, 1994, pp. 205-222), we can see the change which we have revealed -in particular the "additional" sons and daughters of manual workers who have become professionals- as resulting from a change in the distances between social classes due to the increasing size of the category of professionals. This does not, of course, mean that change can be considered to be an artefact or an illusion. Finally, it should be noted that the change in the distances between social classes could be approached as an empirical problem using Goodman's association model or extensions of this involving several dimensions. 
ety is not fixed, that is to say that the inequalities which apply to access to different social positions between individuals from different classes of origin are not inexorably reproduced from one generation to the next, and therefore that societies and their members possess some ability (even limited) to change the social destinations of individuals. It is nevertheless true that the inequality of social opportunity exhibits a high degree of inertia which means that sociologists must use sophisticated methods to reveal the changes it undergoes. However, refuting the theory of temporal invariance does not mean ipso facto that we need to adopt the theory of industrialism or its post-industrial variant ${ }^{(39)}$, which are in our view too teleological and finalistic, predicting the regular and ineluctable fall of inequality of opportunity with the coming of a New Society. As Raymond Boudon emphasized in 1984, there is room for disorder in theories about social change.

In our view, the result of this research may be significant for our understanding of change in French society in the second half of the century. In the case of a statistical association with a high degree of inertia, the methodological innovation, due to Erikson and Goldthorpe and to Xie, which applies a log-multiplicative structure to the interaction with time has proved to be a very powerful tool for revealing shifts which have hitherto gone undetected. It could be of value to apply this methodology to confirm or reject the stability of educational opportunity which recent research claims to have identified. An obvious limitation of this paper is that by concentrating on revealing a long-term trend and testing its robustness it has not formulated, still less tested, any hypothesis to explain the change. This is the task which we must now tackle. An individual's social origin and social destination are separated by his or her education and occupational experience. The 1953 Emploi survey and the 1964 to 1993 Formation - Qualification Professionnelle surveys contain the information needed to test various hypotheses about changes which could have affected intermediate relationships.

While little doubt remains that increasing school attendance and the democratization of education cannot rapidly produce radical changes in the structure of mobility this does not necessarily mean that in the long term they fail to produce any change, as what we have revealed is a slight but continuous unidirectional change towards greater social fluidity, for both men and women over a period of forty years. In this context it is stimulating to re-read Boudon's L'inégalité des chances while bearing in mind Michael Hout's findings for the United States. In American society, the statistical association between social origin and destination is weaker the more highly educated the group considered. Thus, without any change in inequality of educational opportunity or the mechanism by which social positions are allocated on the basis of qualifications, the general rise in the level of education can, on its own, weaken the association between social origin and destination by a compositional effect. It will also be necessary, following recent work by

(39) Daniel Bell wrote that "the post-industrial society, in its initial logic, is a meritocracy" (1973, p. 409). 
Chauvel (1997), to investigate in greater detail the variation in social fluidity from one birth-cohort to another. Much work is still needed to understand what has been the driving force behind change in social inequality in France during the second half of the twentieth century.

\section{Louis-André VALLET}

LASMAS-Institut du Longitudinal - CNRS Membre associé du LSQ-CREST Maison de la Recherche en Sciences Humaines - Université de Caen Esplanade de la Paix - 14032 Caen cedex France vallet@mrsh.unicaen.fr-louis-andre.vallet@wanadoo.fr

Translation: Kevin Riley

Previously published: RFS, 1999, 40,1

\section{REFERENCES}

Becker M. P., Clogg C. C., 1989. - “Analysis of Sets of Two-way Contingency Tables Using Association Models", Journal of the American Statistical Association, 84, 405, pp. 142-151.

Bell D., 1973. - The Coming of Post-Industrial Society. A Venture in Social Forecasting, New York, Basic Books [Vers la société post-industrielle, Paris, Laffont, 1976].

Bertaux D., 1969. - “Sur l'analyse des tables de mobilité sociale”, Revue Française de Sociologie, 10,4, pp. 448-490.

Bishop Y. M. M., Fienberg S. E., Holland P. W., 1975. - Discrete Multivariate Analysis: Theory and Practice, Cambridge, Mit Press.

Blau P. M., Duncan O. D., 1967. - The American Occupational Structure, New York, Wiley.

Boudon R., 1973. - L'inégalité des chances. La mobilité sociale dans les sociétés industrielles, Paris, Colin [2nd ed. 1978, 3rd ed. 1985], [Education, Opportunity, and Social Inequality. Changing Prospects in Western Society, New York, Wiley, 1974].

- 1984. - La place du désordre. Critique des théories du changement social, Paris, Presses Universitaires de France [Theories of Social Change: A Critical Appraisal, London, Blackwell / Polity Press, 1986].

Brésard M., 1950. - “Mobilité sociale et dimension de la famille”, Population, 5, 3, pp. 533-566.

Cautrès B., 1997. - "Modèles log-linéaires et analyse comparative des données d'enquête", Revue Internationale de Politique Comparée, 4, 1, pp. 71-112.

Chauvel L., 1997. - Evolution du système de stratification sociale et succession des cohortes, Lille, Thèse de doctorat de l'Université de Lille I, sous la direction de Michel Forsé.

Chenu A., 1990. - L'archipel des employés, Paris, INSEE (Études).

Cherkaoui M., 1992. - "Mobilité” in R. Boudon (éd.), Traité de sociologie, Paris, Presses Universitaires de France, pp. 153-193.

Clogg C. C., Shihadeh E. S., 1994. - Statistical Models for Ordinal Variables, London, Sage.

Cuin C.-H., 1993. - Les sociologues et la mobilité sociale, Paris, Presses Universitaires de France.

Desabie J., 1954. - “L'enquête par sondage sur l'emploi de juin 1953”, Bulletin Mensuel de Statistique, nouvelle série, INSEE, supplément octobre-décembre, pp. 32-40.

- 1955. - "La mobilité sociale en France", Bulletin de la SEDEIS, 1 er novembre.

Duncan O. D., 1966. - "Methodological Issues in the Analysis of Social Mobility" in N. J. Smelser, S. M. Lipset (eds.), Social Structure and Mobility in Economic Development, Chicago, Aldine, pp. $51-97$. 
Erikson R., 1983. - “Changes in Social Mobility in Industrial Nations: The Case of Sweden", Research in Social Stratification and Mobility, 2, pp. 165-195.

Erikson R., Goldthorpe J.H., 1992. - The Constant Flux. A Study of Class Mobility in Industrial Societies, Oxford, Clarendon Press.

Erikson R., Goldthorpe J. H., Portocarero L., 1979. - "Intergenerational Class Mobility in Three Western European Societies: England, France and Sweden”, British Journal of Sociology, 30, 4, pp. 415-441.

Featherman D. L., Hauser R. M., 1978. - Opportunity and Change, New York, Academic Press.

Forsé M., 1997. - “La diminution de l'inégalité des chances scolaires ne suffit pas à réduire l'inégalité des chances sociales", Revue de l'OFCE, 63, pp. 229-239.

- 1998. - "French Trends in Social and Educational Opportunities, 1982-1997", The Tocqueville Review, 19, 1, pp. 173-186.

Forsé M., Chauvel L., 1995. - “L’évolution de l'homogamie en France. Une méthode pour comparer les diagonalités de plusieurs tables", Revue Française de Sociologie, 36, 1, pp. 123-142.

Fukumoto I. K., Grusky D. B., 1993. - "Social Mobility and Class Structure in Early-industrial France" in A. Miles, D. Vincent (eds.), Building European Society. Occupational Change and Social Mobility in Europe, 1840-1940, Manchester, Manchester University Press, pp. 40-67.

Ganzeboom H. B. G., De Graaf P., 1984. - "Intergenerational Occupational Mobility in the Netherlands in 1954 and 1977: A Loglinear Analysis" in B. F. M. Bakker, J. Dronkers, H. B. G. Ganzeboom (eds.), Social Stratification and Mobility in the Netherlands, Amsterdam, Siswo, pp. 71-90.

Ganzeboom H. B. G., Luijkx R., Róbert P., 1989. - "Trends in Intergenerational Occupational Mobility in Hungary between 1930 and 1989" in Luijkx R., 1994, Comparative Loglinear Analyses of Social Mobility and Heterogamy, Tilburg, Tilburg University Press, pp. 43-75.

Ganzeboom H. B. G., Luijkx R., Treiman D. J., 1989. - "Intergenerational Class Mobility in Comparative Perspective", Research in Social Stratification and Mobility, 8, pp. 3-84.

Goldthorpe J. H., 1980. - Social Mobility and Class Structure in Modern Britain, Oxford, Clarendon Press [2nd ed. 1987].

- 1995. - "Le 'noyau dur': fluidité sociale en Angleterre et en France dans les années 70 et 80 ", Revue Française de Sociologie, 36, 1, pp. 61-79.

Goldthorpe J. H., Payne C., 1986. - "Trends in Intergenerational Class Mobility in England and Wales, 1972-1983”, Sociology, 20, 1, pp. 1-24.

Goldthorpe J. H., Portocarero L., 1981. - "La mobilite sociale en France, 1953-1970 : un nouvel examen", Revue Française de Sociologie, 22, 2, pp. 151-166.

Gollac M., Laulhé P., 1987. - "La transmission du statut social. L'échelle et le fossé", Économie et Statistique, 199-200, pp. 85-93.

Goodman L. A., 1972. - "A General Model for the Analysis of Surveys", American Journal of Sociology, 77, 6, pp. 1035-1086.

- 1979. - "Simple Models for the Analysis of Association in Cross-classifications Having Ordered Categories", Journal of the American Statistical Association, 74, 367, pp. 537-552.

Goux D., Maurin É., 1997a. - “Destinées sociales : le rôle de l'école et du milieu d'origine”, Économie et Statistique, 306, pp. 13-26.

- 1997b. - "Meritocracy and Social Heredity in France: Some Aspects and Trends", European Sociological Revien, 13, 2, pp. 159-177.

Hagenaars J. A., 1990. - Categorical Longitudinal Data. Log-linear Panel. Trend, and Cohort Analysis, London, Sage.

Hauser R. M., Koffel J. N., Travis H. P., Dickinson P. J., 1975. - “Temporal Change in Occupational Mobility: Evidence for Men in the United States", American Sociological Review, 40, 3, pp. 279-297.

Hout M., 1984. - "Status, Autonomy, and Training in Occupational Mobility", American Journal of Sociology, 89, 6, pp. 1379-1409.

- 1988. - "More Universalism, Less Structural Mobility: The American Occupational Structure in the 1980s", American Journal of Sociology, 93, 6, pp. 1358-1400. 
Jones F. L., 1992. - “Common Social Fluidity: A Comment on Recent Criticisms”, European Sociological Review, 8, 3, pp. 233-237.

Jonsson J. O., Mills C., 1993. - "Social Mobility in the 1970s and 1980s: A Study of Men and Women in England and Sweden”, European Sociological Review, 9, 3, pp. 229-248.

Kaelble H., 1981. - Historical Research on Social Mobility: Western Europe and the USA in the Nineteenth and Twentieth Centuries, New York, Columbia University Press.

Kerr C., Dunlop J. T., Harbinson F. H., Myers C. A., 1960. - Industrialism and Industrial Man: The Problems of Labor and Management in Economic Growth, Cambridge, Harvard University Press.

Kurz K., Müller W., 1987. - "Class Mobility in the Industrial World", Annual Review of Sociology, 13, pp. 417-442.

Luijkx R., 1994. - “False and Correct Interpretations of Structural Mobility Parameters” in R. Luijkx, Comparative Loglinear Analyses of Social Mobility and Heterogamy, Tilburg, Tilburg University Press, pp. $211-232$.

Luijkx R., Ganzeboom H. B. G., 1989. - "Intergenerational Class Mobility in the Netherlands between 1970 and 1985. Structural Composition, Structural Differences and Relative Mobility" in W. Jansen, J. Dronkers, K. Verrips (eds.), Similar or Different? Continuities in Dutch Research on Social Stratification and Social Mobility, Amsterdam, Siswo, pp. 5-30.

Mendras H., 1988. - La Seconde Révolution française, 1965-1984, Paris, Gallimard [Social Change in Modern France: Towards a Cultural Anthropology of the Fifth Republic, Cambridge, Cambridge University Press, Paris, Éditions de la Maison des Sciences de l'Homme, 1991].

Merllié D., 1994. - Les enquêtes de mobilité sociale, Paris, Presses Universitaires de France.

Merllié D., Prévot J., 1997. - La mobilité sociale, Paris, La Découverte [1 ${ }^{\text {re }}$ éd. 1991 ].

Miles A., Vincent D. (eds.), 1993. - Building European Society. Occupational Change and Social Mobility in Europe, 1840-1940, Manchester, Manchester University Press.

Parsons T., 1951. - The Social System, Glencoe, Free Press.

Raftery A. E., 1986. - "Choosing Models for Cross-classifications”, American Sociological Review, 51, 1 , pp. 145-146.

- 1995. - "Bayesian Model Selection in Social Research", Sociological Methodology, 25, pp. $111-163$.

Sewell W. H. Jr, 1985. - Structure and Mobility. The Men and Women of Marseille, 1820-1870, Cambridge, Paris, Cambridge University Press \& Éditions de la Maison des Sciences de l'Homme.

Seys B., 1984. - "De l'ancien code à la nouvelle nomenclature des catégories socioprofessionnelles", Économie et Statistique, 171-172, pp. 159-166.

Sorokin P. A., 1927. - Social Mobility, New York, Harper \& Brothers [re-issue Social and Cultural Mobility, Glencoe, Free Press, 1959].

Thélot C., 1982. - Tel père, tel fils ? Position sociale et origine familiale, Paris, Dunod.

- 1983. - "L'évolution de la mobilité sociale dans chaque génération", Économie et Statistique, 161, pp. 3-21.

Treiman D. J., 1970. - "Industrialization and Social Stratification" in E. O. Laumann (ed.), Social Stratification: Research and Theory for the 1970's, Indianapolis, Bobbs-Merrill, pp. 207-234.

Vallet L.-A., 1986. - "Activité professionnelle de la femme mariée et détermination de la position sociale de la famille. Un test empirique : la France entre 1962 et 1982", Revue Française de Sociologie, 27, 4, pp. 655-696.

- 1988. - “L'évolution de l'inégalité des chances devant l'enseignement. Un point de vue de modélisation statistique", Revue Française de Sociologie, 29, 3, pp. 395-423.

- 1991. - La mobilité sociale des femmes en France. La participation des femmes aux processus de mobilité sociale intergénérationnelle, Paris, Thèse de doctorat de l'Université de Paris-Sorbonne, sous la direction de Raymond Boudon.

- 1992. - "La mobilité sociale des femmes en France. Principaux résultats d'une recherche" in L. Coutrot, C. Dubar (éds.), Cheminements professionnels et mobilités sociales, Paris, La Documentation Française, pp. 179-200.

Van Leeuwen M. H. D., Maas I., 1996. - "Long-term Social Mobility: Research Agenda and a Case Study (Berlin, 1825-1957)", Continuity and Change, 11, 3, pp. 399-433. 
Vermunt J. K., 1997. - Log-linear Models for Event Histories, London, Sage.

Weakliem D. L., 1992. - "Comparing Non-nested Models for Contingency Tables", Sociological Methodology, 22, pp. 147-178.

Wong R.S.-K., 1994. - "Postwar Mobility Trends in Advanced Industrial Societies", Research in Social Stratification and Mobility, 13, pp. 121-144.

- 1995. - "Extensions in the Use of Log-multiplicative Scaled Association Models in Multiway Contingency Tables", Sociological Methods \& Research, 23, 4, pp. 507-538.

Wong R.S.-K., Hauser R. M., 1992. - "Trends in Occupational Mobility in Hungary under Socialism", Social Science Research, 2I, 4, pp. 419-444.

Xie Y., 1992. - "The Log-multiplicative Layer Effect Model for Comparing Mobility Tables", American Sociological Review, 57, 3, pp. 380-395. 